\title{
MoP-protected Mo oxide nanotube arrays for long-term stable supercapacitors
}

Bowen Jin, ${ }^{a, b}$ Seyedsina Hejazi, ${ }^{b}$ Hongqi Chu, ${ }^{a}$ Shiva Mohajernia, ${ }^{b}$ Nhat Truong Nguyen, ${ }^{b}$ Min Yang, ${ }^{a *}$ Marco Altomare, ${ }^{b}$ and Patrik Schmuki ${ }^{b, c *}$

${ }^{a}$ MIIT Key Laboratory of Critical Materials Technology for New Energy Conversion and Storage, School of Chemistry and Chemical Engineering, Harbin Institute of Technology, Harbin, 150001, PR China.

b Department of Materials Science, Institute for Surface Science and Corrosion WW4-LKO, University of Erlangen-Nuremberg, Martensstrasse 7, 91058 Erlangen, Germany.

${ }^{c}$ Chemistry Department, Faculty of Sciences, King Abdulaziz University, 80203 Jeddah, Saudi Arabia Kingdom

Corresponding authors: E-mail: $\quad$ yangmin@hit.edu.cn marco.altomare@fau.de

schmuki@ww.uni-erlangen.de

Link to the published articl:

https://www.sciencedirect.com/science/article/pii/S2352940719305621 


\begin{abstract}
In the current energy scenario, electrochemical capacitors hold the promise to fulfil requirements of high power densities, short charging-discharging times, and long lifetimes. For such supercapacitors, $\mathrm{MoO}_{3}$ is one of the most potent candidate as a negative electrode material, due to a very high theoretical charge density ascribed to easily-switchable multiple oxidation states. Nevertheless, the extremely poor electrochemical stability of $\mathrm{MoO}_{3}$ in aqueous electrolytes prevents any practical use. In the present work, we outline a strategy to overcome the poor stability of $\mathrm{MoO}_{3}$ electrodes: we produce by thermal phosphidation an amorphous MoP protective shell on Mo oxide nanotube arrays. This not only leads to an outstanding stability of the electrode but the phosphidized hybrid structures even maintains a capacitance as high as the initial capacitance (i.e. measured before deterioration) of unprotected pure oxide structures: the phosphidized hybrid structure, used as binder-free electrodes, can deliver a non-intercalation-based volumetric capacitance of over $2^{\prime} 000 \mathrm{~F} \mathrm{~cm}^{-3}$ with an outstanding capacitance retention of $\sim 93 \%$ over $10^{\prime} 000$ charging/discharging cycles.
\end{abstract}

Keywords: Mo oxide; MoP; Nanotubes; Electrochemical stability; Volumetric capacitance; Supercapacitor 


\section{Introduction}

Nowadays, efficient and reliable energy storage is of utmost importance:[1,2] capacitors for portable electronics, or for electric/hybrid vehicles, should provide other than a high mass capacitance also a high volumetric performance. In this context, the development of advanced materials featuring functional structures (e.g. 2D materials with high surface area and novel surface charge storage principles [3]) has led to a remarkable progress in the field.[4-8]

Alternatively, 1D nanostructures, e.g. arrays of nanorods, wires and tubes, can provide not only a high surface area, but also an advantageous directional electron transport. Suitable transition metal compounds, e.g. oxides, nitrides and sulfides, can provide high volumetric capacitances as in addition to double layer charging processes, extra charge (pseudocapacitance) can be stored by redox reactions (due to intercalation or surface charging) [9-12] - this holds particularly for compounds that have easily switchable multiple valence states.[13]

Among transition metal oxides, $\mathrm{MoO}_{3}$ has, in principle, a high potential to be used as negative electrode material for capacitors due to its low cost, environmental friendliness and, even more importantly, very high charge storage capacitance. [5,14] However, $\mathrm{MoO}_{3}$ is electrochemically very unstable in acidic aqueous electrolytes. [15-19] This leads to a very poor cyclability and an extremely short electrode lifetime that virtually makes it impossible to use $\mathrm{MoO}_{3}$ directly in a supercapacitor device.

This issue is well known and a number of works in the literature reported on attempts to combine Mo oxide based electrodes with stabilizing or protective materials, to achieve high capacitance and electrochemical robustness at once, however with only limited success.[20-24]

In this work we introduce a MoP surface protection strategy to stabilize Mo oxide nanotube array electrodes for supercapacitors. We selected MoP for different reasons: MoP, particularly in 
the amorphous state, can exhibit a very high electrochemical stability in acidic media.[25,26] Yet, similar to various other transition metal phosphides (Ni, Co, Fe[27], it combines a set of unique properties, such as a ceramic-like hardness and strength and an electrical conductivity comparable to that of metals[28,29] Particularly the electrical conductivity properties of MoP can overcome the limitations in capacitive performance caused by the relatively poor conductivity of Mo oxide. [30,31] Moreover, MoP can be directly formed as a shell on the surface of Mo oxide nanotube arrays by a straightforward phosphidation treatment.

While electrodes fully converted to MoP exhibit a poor charge storage ability (in line with previous work in the literature[32-34]), we found that MoP-protected Mo oxide nanotube layers can be used as binder-free negative electrodes that sustain excellent cyclic stability and rate performance in aqueous $\mathrm{H}_{2} \mathrm{SO}_{4}$ electrolytes, providing volumetric capacitances up to 2'000 $\mathrm{F} \mathrm{cm}^{-3}$ with an outstanding capacitance retention of $93 \%$ over $10^{\prime} 000$ charging/discharging cycles.

\section{Results and Discussion}

In order to grow arrays of self-organized molybdenum oxide nanotubular structures we used electrochemical anodization of Mo metal foils in a fluoride-containing glycerol electrolyte according to a method that was presented in detail in previous work.[35] Note that by this approach the nanotube layers are grown on a conductive substrate (Mo metal), and can therefore be directly used as electrodes for supercapacitors without any binder.

Tube length and diameter can be adjusted by controlling the applied voltage, as shown in Fig. 1 and S1. Fig.1a shows the structure of a typical molybdenum oxide nanotube (NT) layer grown 
at $50 \mathrm{~V}$; these Mo oxide NTs are vertically aligned, and have a length of approximately $1.3 \mu \mathrm{m}$ and an inner diameter of $140 \mathrm{~nm}$.

As-formed NT layers were found to be amorphous (XRD data in Fig. 1b). In previous work, we have shown that these 1D nanostructures can be crystallized to various stoichiometries of Mo oxide (e.g. $\mathrm{MoO}_{2}$ or $\mathrm{MoO}_{3}$ ), or transformed into molybdenum sulfide for electro-catalytic hydrogen evolution.[35] Here, we crystallize the structures by annealing in air or in vacuum, and then expose them to a phosphidation treatment at different temperatures $\left(250-800^{\circ} \mathrm{C}\right)-$ see Experimental Section for more details.

XRD, SEM and EDS data after crystallization and phosphidation are compiled in Fig. 1b,c, Fig. S2, and Table S1. In general, the results demonstrate that we can produce NT layers with tunable crystalline phase and chemical composition by adjusting the phosphidation conditions (details in the SI). In the present study we selected an annealing in vacuum followed by a phosphidation at $300^{\circ} \mathrm{C}$ for further work as electrodes produced under these conditions were found to deliver not only the best cycling stability but also a remarkable electrochemical performance (as will be discussed below).

XRD analysis (Fig. 1b) reveals that a preliminary thermal treatment in vacuum at $350^{\circ} \mathrm{C}$ leads to crystalline structures composed of a sub-stoichiometric $\mathrm{Mo}_{4} \mathrm{O}_{11}$ cubic phase. When phosphidized at $300^{\circ} \mathrm{C}$, these NTs are converted into monoclinic $\mathrm{MoO}_{2}$ phase. While no MoP XRD reflections can be seen, EDS analysis reveals an increased $\mathrm{P}$ content up to 30 at\%. SEM and optical images of such NT layers are shown in Fig. 1c. An evident change of the color of the layer can be appreciated with the unaided eye (optical image); only minor morphological modifications take place at the nanoscale. 
We characterized the oxide NT layers crystallized in vacuum (reference) and the nanostructures phosphidized at $300^{\circ} \mathrm{C}$ by HR-TEM, SAED, and EDS mapping (Fig. $1 \mathrm{~d}-\mathrm{k}$ ).

TEM analysis (Fig. 1d and e, respectively) confirms the nanotubular morphology of the Mo oxide structures. For the unprotected oxide NTs, the lattice fringes have a $d$ spacing of $0.279 \mathrm{~nm}$, which corresponds to the $\left(\begin{array}{lll}2 & 1 & 2\end{array}\right)$ plane of $\mathrm{Mo}_{4} \mathrm{O}_{11}$. This is in line with a $\mathrm{Mo}_{4} \mathrm{O}_{11}$ composition revealed also by XRD. The situation is different for phosphidized structures: firstly, the nanotubes carry along their walls a thin (few nm-thick) amorphous surface layer. In addition, the lattice fringes are only visible in the subsurface of the nanotubes ("core"), and have a $d$ spacing value of $0.342 \mathrm{~nm}$ that can be attributed to the $\left(\begin{array}{lll}0 & 1 & 1\end{array}\right)$ plane of $\mathrm{MoO}_{2}$, respectively. This corroborates the XRD results, and supports the conversion of $\mathrm{Mo}_{4} \mathrm{O}_{11}$ to $\mathrm{MoO}_{2}$.

The SAED pattern of reference nanotubes exhibit well defined bright rings, in line with the polycrystalline nature of the $\mathrm{Mo}_{4} \mathrm{O}_{11}$ nanotubes. The diffraction signals are indexed to various crystallographic planes of $\mathrm{Mo}_{4} \mathrm{O}_{11}$ (Fig. 1f). In contrast, the SAED pattern of MoP-protected oxide nanotubes show both diffraction rings and diffuse halos (Fig. 1g). The former are assigned to (0 1 1), (-2 12 2 $),\left(\begin{array}{lll}-2 & 0 & 2\end{array}\right),\left(\begin{array}{lll}-2 & 2 & 2\end{array}\right)$ and (-2 $\left.3 \begin{array}{lll}-2 & 1\end{array}\right)$ planes of $\mathrm{MoO}_{2}$, while the latter are due to the presence of a non-crystalline phase. The presence of $\mathrm{Mo}, \mathrm{O}$ and $\mathrm{P}$ in the phosphorous-treated nanostructures is confirmed by TEM-EDS mapping (Fig. 1h-k). The data, overall, point to the coexistence in the nanotube structures of a crystalline $\mathrm{MoO}_{2}$ core and an amorphous MoP shell.

We used XPS analysis to clarify the effects of phosphidation at different temperatures on the NT chemical composition (data in Fig. 2 and Table S2). The deconvolution of the Mo3d XPS signal (Fig. 2a) reveals the presence of a predominant Mo3d doublet peaking at $228.7 \mathrm{eV}$ and $231.9 \mathrm{eV}$ $\left(\mathrm{Mo}^{\delta+} 3 \mathrm{~d}_{5 / 2}\right.$ and $\left.3 \mathrm{~d}_{3 / 2}\right)$, which according to data in the literature[36] can be assigned to the Mo-P bond 
$\left(\mathrm{Mo}^{\delta+} 1 \leq \delta \leq 4\right)$, while the peaks at $229.8 \mathrm{eV}$ and $233.2 \mathrm{eV}$ fit well to $\mathrm{MoO}_{2}\left(\mathrm{Mo}^{4+} 3 \mathrm{~d}_{5 / 2}\right.$ and $\left.3 \mathrm{~d}_{3 / 2}\right),[37]$ and those at $231.4 \mathrm{eV}$ and $234.8 \mathrm{eV}$ can be ascribed to $\mathrm{Mo}^{5+} 3 \mathrm{~d}_{5 / 2}$ and $3 \mathrm{~d}_{3 / 2}$ signals; [38] i.e. the Mo oxide nanotube surface is converted into amorphous MoP, and the Mo(IV) and Mo(V) signals are ascribed to the subsurface oxide $\left(\mathrm{MoO}_{2}\right.$ core $)$. A partial surface oxidation of the amorphous MoP layer under ambient conditions may also be taken into account.[39] The P2p XPS data in Fig. 2b fit well to the Mo3d XPS results (Fig. 2a): the P2p spectrum exhibits two closely spaced spin orbit signals at B.E. values of $129.5 \mathrm{eV}$ and $130.4 \mathrm{eV}\left(2 \mathrm{P}_{3 / 2}, 2 \mathrm{P}_{1 / 2}\right)$, to be assigned to MoP. The peaks at $132.7 \mathrm{eV}$ and $133.8 \mathrm{eV}\left(2 \mathrm{P}_{3 / 2}, 2 \mathrm{P}_{1 / 2}\right)$ are instead attributed to oxygenated $\mathrm{P}$ species (possible surface oxidation in air).[40,41]

The XPS data in Fig. S3 (along with data in Fig. 2a) outline the evolution of the NT composition with various thermal treatments. Overall, the data confirm the phosphidation at $300^{\circ} \mathrm{C}$ to form $\mathrm{MoO}_{2}-\mathrm{MoP}$ "core-shell" NT structures (details in the SI). The composition homogeneity of the MoP-protected NTs was assessed by XPS depth profile (Fig. 2c). The distribution of Mo and O across the NT layers is uniform; the P content decreases gradually towards the bottom of the tubular structures while approaching the Mo metal substrate. Given that for phosphidation the P-precursor is distributed over the sample surface (see Experimental Section), it is reasonable to assume that the MoP formation occurs along the depth of the NTs at gradually smaller extents.

We characterized these structures in view of their electrochemical performance; preliminary tests were conducted to evaluate the electrode stability. The volumetric capacitance (discussed later and shown in Fig. 4) was obtained by integrating the area within the $\mathrm{CV}$ (Fig. S4). For pure $\mathrm{MoO}_{3}$, the first CV shows (Fig. S4a), as expected, a high charge, but this capacitance can be delivered only for a few 100s cycles and then dramatically decays to much lower values; the CV plots 
recorded over 5000 cycles show that the capacitance drop after 1000 cycles is $\sim 70 \%$ of the initial charge storage (Fig. S4). On the contrary, for the MoP-protected Mo oxide NT electrodes the CV curves remain virtually identical over $10^{\prime} 000$ cycles (Fig. S4). The CV characteristics point to a non-intercalation-based capacitance, that can be ascribed e.g. to double layer charging in combination with other fast surface charging processes. [13]

To avoid electrode degradation while maintaining a high capacity during long-term cycling, a suitable potential window was found to be in the $-0.4-+0.2 \mathrm{~V}$ (Fig. S5); more cathodic or anodic voltages were found to lead to irreversible redox reactions and gas evolution, which undermine the chemical nature and mechanical stability of the NT electrodes. Particularly, we observed high cathodic currents and severe $\mathrm{H}_{2}$ gas evolution at $-0.6 \mathrm{~V}$ (vs. $\mathrm{Ag} / \mathrm{AgCl}$ ) that led to delamination of the active electrode material from the metal substrate (Fig. S5).

We then optimized the nanotube morphology (tube length and diameter; Fig. S6), and screened different conditions for the crystallization step prior to phosphidation (Fig. S1). The areal capacitance reaches the maximum, $\sim 40 \mathrm{mF} \mathrm{cm}^{-2}$ (at $100 \mathrm{mV} \mathrm{s}^{-1}$ ), for Mo oxide NTs grown at $50 \mathrm{~V}$ (CV data in Fig. S4). Such NTs have diameter and length of $140 \mathrm{~nm}$ and $1.3 \mu \mathrm{m}$, respectively (Fig. S1).

As shown below in more detail, key to simultaneously reach cycling stability and high capacitance is the phosphidation treatment, which has to be optimized, and combined to a suitable preliminary crystallization of the nanotubes. When subsequently phosphidized at $300^{\circ} \mathrm{C}$, the NTs pre-crystallized in vacuum $\left(350^{\circ} \mathrm{C}\right)$ perform better than those pre-crystallized in air (Fig. S7).

In Fig. 3a-c and Fig. S8 we have compiled the galvanostatic charge-discharge (GCD) profiles collected at different current densities (1-100 A cm$~_{-3}$ range) in $1 \mathrm{M} \mathrm{H}_{2} \mathrm{SO}_{4}$ for NT structures crystallized and phosphidized at different temperatures. 
In general, the profiles show close to an ideal triangular capacitive behavior, i.e. are almost symmetric at different current densities - this proves high coulomb efficiency during the charging/discharging process. iR drop becomes slightly noticeable only at high current densities, i.e. $100 \mathrm{~A} \mathrm{~cm}^{-3}$ (Fig. 3a). It is evident that Mo oxide NTs phosphidized at $300^{\circ} \mathrm{C}$ outperform electrodes treated at other temperatures (Fig. 3b), delivering a volumetric capacitance over $2^{\prime} 000 \mathrm{~F} \mathrm{~cm}^{-3}$ (precisely, $2^{\prime} 044 \mathrm{~F} \mathrm{~cm}^{-3}$ at $1 \mathrm{~A} \mathrm{~cm}^{-3}$ ) and a mass capacitance of $817.6 \mathrm{~F} \mathrm{~g}^{-1}$ - see the $\mathrm{Sl}$ and data in Fig. S9 and S10 for calculation of mass and volumetric capacitance. Such a performance is comparable to that of best non-noble metal electrodes of a similar thickness (a comparison is given in Table S3).

The volumetric capacitance of MoP-protected NTs is $~ 2.5$ times higher than that of a phosphidized nanoporous Mo oxide electrode with comparable thickness (1.5 $\mu \mathrm{m})$. The morphology of the reference nanoporous electrode, XRD characterization and electrochemical performance (before and after MoP protection) are compiled in Fig. S11. The significantly higher capacitance of phosphidized NTs arises from their 1D morphology, which provides direct pathways for charge transport through the conductive MoP shell.

The rate performance is also remarkable (Fig. 3c): a volumetric capacitance of $\sim 1^{\prime} 458 \mathrm{~F} \mathrm{~cm}^{-3}$ can be measured at a hundredfold higher current density, that is, the phosphidized Mo oxide NTs deliver at $100 \mathrm{~A} \mathrm{~cm}^{-3}$ a $~ 71 \%$ volumetric capacitance retention.

We grew NTs of various thicknesses, i.e. $0.65,1.3$ and $3.2 \mu \mathrm{m}$, and phosphidized them under optimized conditions (MoP protection at $300^{\circ} \mathrm{C}$ ) - their SEM characterization and electrochemical performance are compiled in Fig. S12. The favorable rate performance and high volumetric capacitance still remain, with a minor influence of the layer thickness: even in the case of $3.2 \mu \mathrm{m}-$ thick electrodes, volumetric capacitances of $\sim 1^{\prime} 800 \mathrm{~F} \mathrm{~cm}^{-3}$ can be achieved - such capacitance is 
still comparable with those reported for best performing electrodes of a comparable thickness. $[5,8,42,43]$

We characterized the electrodes by EIS and dynamic contact angle analysis. MoP-protected structures display in the Nyquist plot (Fig. 3d) almost vertical profiles, and no evident features attributable to a charge transfer resistance can be identified. The Bode plot in Fig. S13 shows that for phosphidized $\mathrm{NTs}\left(\mathrm{T} \geq 300^{\circ} \mathrm{C}\right)$ the phase angle at low frequencies exceeds $80^{\circ}$.[44] Overall, these results confirm the capacitive nature of phosphidized electrodes. In contrast, the EIS results for Mo oxide electrodes (vacuum-crystallized) strongly deviate from an ideal capacitor behavior (e.g. low frequency phase angle of $\sim 65^{\circ}$; Fig. S13). In addition, $\mathrm{P}-\mathrm{MoO}_{\mathrm{x}}$ electrodes are hydrophilic in nature; dynamic contact angle results (Fig. S14) show an enhanced wettability for electrodes phosphidized at $300^{\circ} \mathrm{C}$ compared to pure oxide structures[45] - the hydrophilicity is indeed beneficial for an excellent wetting of the electrode.

We further characterized these structures by cyclic voltammetry (CV), at different scan rates in the $10-200 \mathrm{mV} \mathrm{s}^{-1}$ range, in $1 \mathrm{M}$ sulfuric acid $\left(\mathrm{H}_{2} \mathrm{SO}_{4}\right)$. The results for Mo oxide NTs crystallized in vacuum and subsequently phosphidized for MoP protection at $300^{\circ} \mathrm{C}$ are shown in Fig. $4 \mathrm{a}$, and $\mathrm{CV}$ and rate capability results of electrodes phosphidized at various temperatures $\left(250-800^{\circ} \mathrm{C}\right.$ range $)$ are presented for comparison in Fig. 4b and Fig. S15. Well in line with the GCD data discussed above, the phosphidation at $300^{\circ} \mathrm{C}$ leads to the highest capacitance response among the phosphidized electrodes: at low scan rates, e.g. 20 or $10 \mathrm{mV} \mathrm{s}^{-1}$, the volumetric capacitance reaches $1^{\prime} 500 \mathrm{~F} \mathrm{~cm}^{-3}$ or even higher values, respectively (Fig. 4b). A good rate handling ability is observed (62 \% at 200 $\mathrm{mV} \mathrm{s} \mathrm{s}^{-1}$ ). Although structures phosphidized at other temperatures than $300^{\circ} \mathrm{C}$ deliver a lower capacitance, the CV data are in any case characterized by a classic rectangular-shaped curve, even 
when recorded at high scan rates. When the phosphidation temperature is $800^{\circ} \mathrm{C}$, the P-modified electrodes are found to induce hydrogen evolution reaction at negative potentials; the reaction onset is at $\sim-0.3 \mathrm{~V}$ (Fig. S15e); i.e. a complete conversion of the oxide NTs into MoP is not beneficial to the capacitance performance, which is in line with previous work in the literature on pure MoP [32-34]. This demonstrates the synergistic, highly beneficial interaction of the hybrid Mo-oxide/MoP-structure.

Key to a practical use of supercapacitor electrodes is the electrochemical robustness. Therefore, the NT array electrodes were explored not only for their capacitance performance but, more importantly, for their stability in long-term cycling by continuous CV measurements. Degradation tests recorded over 10'000 consecutive CV cycles (at $100 \mathrm{mV} \mathrm{s}^{-1}$ ) demonstrate an outstanding stability of the MoP-protected Mo oxide NTs (Fig. 4c): $93 \%$ of the initial volumetric capacitance ( 1'040 $\left.\mathrm{F} \mathrm{cm}^{-3}\right)$ is retained; this is in stark contrast to the performance of unprotected oxide NTs, which show a dramatic decline of the capacitance to $~ 30 \%$ of the initial performance (373 $\mathrm{F} \mathrm{cm}^{-3}$ ) already after a few 1000 s cycles.

To shed light on the different electrochemical stability, both oxide and MoP-protected electrodes were characterized post-mortem by SEM and EIS. SEM analysis of the phosphidized electrodes (Fig. S16) proves that no evident morphological alteration of the NT structures has occurred after long term cycling. Also, EIS data after cycling are virtually identical to those of a fresh electrode; that is, these structures do not exhibit any substantial loss of charge storage ability (Fig. S17a). Contrarily, EIS data for cycled, unprotected Mo oxide NTs indicate a substantial degradation of the capacitance (Fig. S17b). Evidently, the MoP shell is key to provide the electrodes with remarkable robustness to long time cycling and high current density operation, by protecting the Mo oxide NT core from electrochemical degradation. In addition, the MoP protective shell can also contribute 
to the enhanced electrochemical performance with its electronic conductivity, which allows to overcome performance limits ascribed to the relatively poor conductivity of pure Mo oxide.

Finally, we quantified the capacitive and diffusion limited contributions to the total capacitance; for this, we used an approach outlined in previous work.[46] The results of such analysis, summarized in Fig. $4 \mathrm{~d}$, show that at a scan rate of $2 \mathrm{mV} \mathrm{s}^{-1}$ there is a minor contribution of diffusion-limited processes. Such contribution equals $\sim 7 \%$ of the total capacitance, and the performance is thus mainly dominated by surface capacitive effects, whether electrostatic or pseudocapacitive. ${ }^{[35]}$ At a scan rate of $10 \mathrm{mV} \mathrm{s}^{-1}$, the diffusion limited contributions to the total capacitance results even smaller, that is, the total capacitance is at high charge/discharge rates hardly influenced by diffusion-limited processes, $[47,48]$ and the charge storage mechanism is therefore almost completely provided by non-intercalation based capacitance or surface redox reactions.

\section{Conclusions}

In summary, we outlined a strategy to stabilize Mo oxide nanostructured electrodes for highperformance supercapacitors based on acidic aqueous electrolytes. For this, we produced firstly arrays of anodically grown Mo oxide nanotubes. These structures were then protected with a few nm-thick amorphous MoP shell by an optimized thermal phosphidation treatment. The result is binder free negative electrodes that not only delivered a volumetric capacitance over $2^{\prime} 000 \mathrm{~F} \mathrm{~cm}^{-3}$ in acidic aqueous electrolytes, i.e. a performance comparable to best performing non-noble metal

electrodes reported to date, but also provided long time cyclability and robustness to high current 
density operation; it is remarkable that a capacitance retention as high as $>90 \%$ could be measured after 10’000 charging/discharging cycles.

Our results make clear that surface protection strategies, namely by the design of hybrid oxide/phosphide nano-architectures of multivalent transition metals, will provide a generic approach to stabilize efficient capacitive materials, and will therefore be key to tackle new challenges in the field of electrochemical energy storage. 


\section{Experimental Section}

Fabrication of Mo oxide NT electrodes

One dimensional self-ordered molybdenum oxides were prepared by anodization as outlined in previous work.[35] Briefly, $0.2 \mathrm{~mm}$ thick Mo foils (Sigma Aldrich) were cleaned by ultrasonication in acetone (Emsure), ethanol (Emsure), and distilled water for 10 minutes each. The foils were successively dried in a $\mathrm{N}_{2}$ stream. Anodization was performed in a two-electrode electrochemical cell. The Mo foil was used as anode and a platinum electrode was used as a counter electrode. The electrolyte used for anodization was composed of 90:10 vol\% glycerol (Sigma Aldrich)/ $\mathrm{H}_{2} \mathrm{O}$ mixture, containing 10 vol\% $\mathrm{H}_{2} \mathrm{O}, 0.4 \mathrm{M} \mathrm{NH}_{4} \mathrm{~F}$ (Roth) and $0.1 \mathrm{M}\left(\mathrm{NH}_{4}\right)_{2} \mathrm{SO}_{4}$ (Sigma Aldrich). The duration of the anodic growth was of $1 \mathrm{~h}$. After anodization, the anodic layers were kept in the electrolyte for 10 minutes, and were then immersed in ethanol to remove residue of the electrolyte. The layers were then dried with $\mathrm{N}_{2}$ gas.

Fabrication of Mo oxide nanoporous (reference) electrode

The nanoporous Mo oxide electrodes were prepared as outlined in previous work.[49] Briefly, cleaned molybdenum foils were anodized in an aqueous electrolyte containing $0.15 \mathrm{M}$ oxalic acid, $0.01 \mathrm{M} \mathrm{NaF}$ and $0.1 \mathrm{M} \mathrm{Na}_{2} \mathrm{SO}_{4}$. The anodization was carried out at a constant current density of $25 \mathrm{~mA} \mathrm{~cm}^{-2}$ for $20 \mathrm{~min}$. The resulting anodic layers were $1.5 \mu \mathrm{m}$-thick (see data in Fig. S11).

Crystallization and phosphidation (MoP protection) of the oxide NT layers

Prior to phosphidation, amorphous oxide NT and nanoporous oxide electrodes were converted into $\alpha \mathrm{MoO}_{3}\left(\mathrm{Mo}(\mathrm{VI})\right.$; JCPDS Card No. 05-0508) by annealing in air $\left(350^{\circ} \mathrm{C}\right)$, or were crystallized in 
vacuum $\left(350^{\circ} \mathrm{C}\right)$ to form a sub-stoichiometric $\mathrm{Mo}_{4} \mathrm{O}_{11}$ cubic phase (Mo(VI) and $\mathrm{Mo}(\mathrm{V})$; JCPDS Card No. 73-1538). The structures were then MoP-protected by a phosphidation treatment: the layers were covered with $\mathrm{NaH}_{2} \mathrm{PO}_{2} \cdot \mathrm{H}_{2} \mathrm{O}$ powder, and were annealed in vacuum at different temperatures $\left(250-800^{\circ} \mathrm{C}\right)$. Finally, the structures were washed with water in an ultrasonic bath to remove the unreacted salt and by-products (e.g. phosphates). Reference Mo oxide layers (unprotected) were prepared by annealing the structures for a second time at $350^{\circ} \mathrm{C}$, in vacuum.

\section{Characterization of the structures}

A field-emission scanning electron microscope (FE-SEM, Hitachi S4800, and Supra TM55, Zeiss) and a transmission electron microscope (TEM TITAN 60-300, FEI, USA) were used to characterize the morphology (SEM, TEM and HAADF-TEM), crystallographic features (HR-TEM and SAED) and chemical composition (EDS-SEM and EDS-TEM mapping) of the samples. X-ray diffraction (XRD) carried out with an X'pert Philips MPD diffractometer (equipped with a Panalytical X'celerator detector), and with a D8-Advance diffractometer (Bruker) was employed to examine the crystallographic properties of the materials, using $\mathrm{Cu}$ K $\alpha$ radiation $(\lambda=0.1506 \mathrm{~nm})$. The chemical composition of the samples was analyzed by X-ray photoelectron spectroscopy (XPS, PHI 5600, US) and peak positions were calibrated with respect to the C1s peak at $284.8 \mathrm{eV}$.

\section{Electrochemical measurements}

Cyclic voltammetry (CV) and electrochemical impedance spectroscopy (EIS) analyses were conducted using a Zahner electrochemical workstation. Galvanostatic charge-discharge (GCD) measurements were performed using an Autolab potentiostat. In any case a three electrode 
electrochemical cell was used. The Mo oxide and phosphide layers were used as working electrodes; they were pressed against an O-ring-sealed opening in the wall of the electrochemical cell. The electrode nominal area exposed to the electrolyte was $0.62 \mathrm{~cm}^{2}$. A graphite electrode was used as a counter electrode. As reference electrode, a $\mathrm{Ag} / \mathrm{AgCl}$ ( $3 \mathrm{M} \mathrm{KCl}$ ) electrode was used. $1 \mathrm{M} \mathrm{H}_{2} \mathrm{SO}_{4}$ aqueous solution was used as electrolyte. $\mathrm{CV}$ was recorder at different scan rates in the 10-200 $\mathrm{mV} \mathrm{s}^{-1}$ range. Galvanostativ cycling was performed at current densities from 1 to $100 \mathrm{~A} \mathrm{~cm}^{-}$ ${ }^{3}$. EIS was carried out in the $100 \mathrm{kHz}$ to $10 \mathrm{mHz}$ frequency range, using a potential amplitude of 10 $\mathrm{mV}$. The spectra were recorded at the open circuit potential ( $100 \mathrm{mV}$ vs. Ag/AgCl).

Active electrode material weight:

The weight of the active electrode material was estimated according to the following two approaches:

1. After growth, crystallization and phosphidation, the $\mathrm{MoP}-\mathrm{MoO}_{\mathrm{x}}$ nanotube electrodes (supported by Mo foil) were weighted with a balance with $0.01 \mathrm{mg}$ resolution. Then, the electrodes were cathodically polarized, at $-1.8 \mathrm{~V}$ v $\mathrm{AgCl} / \mathrm{Ag}$, in $1 \mathrm{M} \mathrm{KOH}$ for 3 minutes. The treatment induced strong gas evolution that combined to a subsequent sonication step led to complete removal of the MoP-MoOx NT layers, leaving behind pristine Mo metal substrates (see Fig. S9). The Mo metal substrates were then weighted. The weight difference (before and after the treatment) provided the mass of the $\mathrm{MoP}-\mathrm{MoO}_{\mathrm{x}}$ active electrode material. This procedure was done for ten samples. The average mass of one $\mathrm{MoP}-\mathrm{MoO}_{\mathrm{x}}$ nanotube layer was $0.20 \mathrm{mg}$. 
2. The mass of the active electrode material was calculated from the SEM image of a MoP protected Mo oxide nanotube layer, according to the equation below:

$$
\mathrm{m}=\rho \mathrm{V}=\rho\left(\mathrm{V}_{\text {bulk }}-\mathrm{V}_{\text {pores }}\right)=(1-\mathrm{n}) \rho \mathrm{V}_{\text {bulk }}
$$

where $\rho$ is the density of $\mathrm{P}-\mathrm{MoO}_{\mathrm{x}}\left(\rho_{\mathrm{MoO}}=6.47 \mathrm{~g} / \mathrm{cm}^{3}\right.$ and $\left.\rho_{\mathrm{MoP}}=7.34 \mathrm{~g} / \mathrm{cm}^{3}\right)$; $V_{\text {bulk }}$ is the volume of the electrode layer without pores $\left(\sim 8 \cdot 10^{-5} \mathrm{~cm}^{3}\right), V_{\text {pores }}$ is the overall volume of pores $\left(4.8 \cdot 10^{-5} \mathrm{~cm}^{3}\right)$; and $\mathrm{n}$ is the ratio of pore volume vs. whole electrode volume (including porosity). The latter were determined from the SEM image in Fig. 1 and Fig. S10. The estimated porosity was $\sim 60 \%$. The calculated active material mass of one electrode is in the 0.21-0.23 mg range, the former assuming the whole electrode to be composed of oxide only, the latter of MoP only; the results fit well to the mass determined as outlined by approach 1 (0.20 mg).

These results refer to NT electrode grown with an anodization voltage of $50 \mathrm{~V}$ for $1 \mathrm{~h}$; the anodic area was $0.62 \mathrm{~cm}^{2}$. The NT were grown to a length (NT layer thickness) of ca. $1.3 \mu \mathrm{m}$.

\section{Capacitance calculations}

The areal and volumetric capacitances of the electrodes were calculated based on CV curves as follows:

Areal Capacitance: $\quad \mathrm{C}_{\mathrm{s}}=\frac{1}{A\left(V_{2}-V_{1}\right) \frac{d V}{d t}} \int_{V_{1}}^{V_{2}} I(V) d V$

Volumetric Capacitance: $\quad \mathrm{C}_{\mathrm{v}}=\frac{C_{s}}{d}$ 
Where $C_{s}$ is area capacitance of the sample, $A$ is the sample area, I (V) is the corresponding current when applying different voltage in $C V$ test, $\frac{d V}{d t}$ is the scan rate of the $C V$ test, $V_{1}$ and $V_{2}$ are the integration potential limits of the test, and $d$ is the thickness of the film. ${ }^{[42]}$

The thickness of the unprotected and MoP-protected Mo oxide NT electrodes was calculated by measuring the layer cross-section by SEM analysis (data in Fig. 1b and Fig. S1). Their average thickness was approximately $1.3 \mu \mathrm{m}$. The volume of the active electrode material is estimated to be $\sim 8.0 \cdot 10^{-5} \mathrm{~cm}^{3}$.

The volumetric and specific capacitance of the electrodes were also calculated based on the GCD curves as follows:

$$
\begin{gathered}
\mathrm{C}_{\mathrm{V}}=\frac{\mathrm{I}}{\mathrm{V}_{M o P-M o o_{x}}} \frac{\left(t_{1}+t_{2}\right)}{2\left(V_{1}-V_{2}\right)} \\
C_{m}=\frac{\mathrm{I}}{\mathrm{m}_{M o P-M o o_{x}}} \frac{\left(t_{1}+t_{2}\right)}{2\left(V_{1}-V_{2}\right)}
\end{gathered}
$$

Where I(A) is the charge/discharge current, $\mathrm{V}_{M o P-M o o_{x}}\left(\mathrm{~cm}^{3}\right)$ is the volume of the active electrode material, $\mathrm{m}_{P-M o o_{x}}(\mathrm{~g})$ is the mass of the active electrode material, $\mathrm{t}_{1}(\mathrm{~s})$ and $\mathrm{t}_{2}(\mathrm{~s})$ are charge and discharge time respectively and $V_{1}(V)$ and $V_{2}(V)$ are the potential limited.

Analysis of the limiting processes for charge storage

Examination of the voltammetric sweep rate dependence of the CV profiles allows to quantitatively distinguish the capacitive contribution to the current response.[46] The current response at a fixed potential can be expressed as follows, i.e. as being the combination of two separate mechanisms, namely surface capacitive effects and diffusion-controlled processes:

$$
\mathrm{i}(\mathrm{V})=k_{1} v+k_{2} v^{\frac{1}{2}}
$$


where $k_{1} v$ and $k_{2} v^{1 / 2}$ correspond to the current contributions from the surface capacitive effects and the diffusion-controlled process, respectively. $k_{1}$ and $k_{2}$ were thus determined to quantify, in a specific potential window, the fraction of the current due to each of these contributions.[46] 


\section{Data Availability}

The data used to support the findings of this study are available from the corresponding author upon request.

\section{Acknowledgements}

The authors would like to acknowledge the ERC, the DFG, the DFG cluster of excellence "Engineering of Advanced Materials" for financial support. B.J., H.C. and M.Y. thank the National Natural Science Foundation of China (No.21773046), and the China Scholarship Council (CSC)

for financial support. The authors thank also Anja Friedrich and Helga Hildebrand (University of Erlangen-Nuremberg, Germany) for SEM and XPS analyses. 


\section{References}

[1] P. Simon, Y. Gogotsi, Materials for electrochemical capacitors, Nature Materials. 7 (2008) 845-854.

[2] A.S. Arico, P. Bruce, B. Scrosati, J.-M. Tarascon, W. Van Schalkwijk, Nanostructured materials for advanced energy conversion and storage devices, Nature Materials. 4 (2005) 336-377.

[3] L. Peng, Z. Fang, Y. Zhu, C. Yan, G. Yu, Holey 2D Nanomaterials for Electrochemical Energy Storage, Advanced Energy Materials. 8 (2018) 1702179. doi:10.1002/aenm.201702179.

[4] M.R. Lukatskaya, O. Mashtalir, C.E. Ren, Y. Dall'Agnese, P. Rozier, P.L. Taberna, M. Naguib, P. Simon, M.W. Barsoum, Y. Gogotsi, Cation intercalation and high volumetric capacitance of two-dimensional titanium carbide, Science. 341 (2013) 1502-1505.

[5] M.R. Lukatskaya, S. Kota, Z. Lin, M.-Q. Zhao, N. Shpigel, M.D. Levi, J. Halim, P.-L. Taberna, M.W. Barsoum, P. Simon, Ultra-high-rate pseudocapacitive energy storage in two-dimensional transition metal carbides, Nature Energy. 2 (2017) 17105.

[6] M. Ghidiu, M.R. Lukatskaya, M.-Q. Zhao, Y. Gogotsi, M.W. Barsoum, Conductive twodimensional titanium carbide 'clay'with high volumetric capacitance, Nature. 516 (2014) 78.

[7] J. Halim, S. Kota, M.R. Lukatskaya, M. Naguib, M. Zhao, E.J. Moon, J. Pitock, J. Nanda, S.J. May, Y. Gogotsi, Synthesis and characterization of 2D molybdenum carbide (MXene), Advanced Functional Materials. 26 (2016) 3118-3127.

[8] A. VahidMohammadi, J. Moncada, H. Chen, E. Kayali, J. Orangi, C.A. Carrero, M. Beidaghi, Thick and freestanding MXene/PANI pseudocapacitive electrodes with ultrahigh specific capacitance, Journal of Materials Chemistry A. 6 (2018) 22123-22133.

[9] W. Zuo, R. Li, C. Zhou, Y. Li, J. Xia, J. Liu, Battery-Supercapacitor Hybrid Devices: Recent Progress and Future Prospects, Advanced Science. 4 (2017) 1600539.

[10] T. Brousse, D. Bélanger, J.W. Long, To be or not to be pseudocapacitive?, Journal of The Electrochemical Society. 162 (2015) A5185-A5189.

[11] Y. Gogotsi, R.M. Penner, Energy Storage in Nanomaterials-Capacitive, Pseudocapacitive, or Battery-like?, ACS Nano. 12 (2018) 2081-2083.

[12] M.R. Lukatskaya, S. Bak, X. Yu, X. Yang, M.W. Barsoum, Y. Gogotsi, Probing the Mechanism of High Capacitance in 2D Titanium Carbide Using In Situ X-Ray Absorption Spectroscopy, Advanced Energy Materials. 5 (2015) 1500589. doi:10.1002/aenm.201500589.

[13] M. Salanne, B. Rotenberg, K. Naoi, K. Kaneko, P.-L. Taberna, C.P. Grey, B. Dunn, P. Simon, Efficient storage mechanisms for building better supercapacitors, Nature Energy. 1 (2016) 16070.

[14] H. Ma, D. Kong, Y. Xu, X. Xie, Y. Tao, Z. Xiao, W. Lv, H.D. Jang, J. Huang, Q. Yang, Disassembly-Reassembly Approach to RuO2/Graphene Composites for Ultrahigh Volumetric Capacitance Supercapacitor, Small. 13 (2017) 1701026.

[15] O. Zelaya-Angel, C. Menezes, F. Sánchez-Sinencio, G.F.L. Ferreira, Electron diffusion and electrochromism in MoO 3 amorphous films, Journal of Applied Physics. 51 (1980) 6022-6026. doi:10.1063/1.327525.

[16] T.M. McEvoy, K.J. Stevenson, J.T. Hupp, X. Dang, Electrochemical Preparation of 
Molybdenum Trioxide Thin Films: Effect of Sintering on Electrochromic and Electroinsertion Properties, Langmuir. 19 (2003) 4316-4326. doi:10.1021/la027020u.

[17] X. Wu, Q. Wang, W. Zhang, Y. Wang, W. Chen, Nanorod structure of Polypyrrolecovered MoO 3 for supercapacitors with excellent cycling stability, Materials Letters. 182 (2016) 121-124. doi:10.1016/j.matlet.2016.05.176.

[18] F. Endres, G. Schwitzgebel, Cyclic voltammetry of polyethylene stabilized hydrogen molybdenum bronzes, Journal of Electroanalytical Chemistry. 415 (1996) 23-26.

[19] H.-S. Kim, J.B. Cook, H. Lin, J.S. Ko, S.H. Tolbert, V. Ozolins, B. Dunn, Oxygen vacancies enhance pseudocapacitive charge storage properties of $\mathrm{MoO} 3-\mathrm{x}$, Nature Materials. 16 (2017) 454-460. doi:10.1038/nmat4810.

[20] W. Yang, J. Xiao, Y. Ma, S. Cui, P. Zhang, P. Zhai, L. Meng, X. Wang, Y. Wei, Z. Du, B. Li, Z. Sun, S. Yang, Q. Zhang, Y. Gong, Tin Intercalated Ultrathin MoO 3 Nanoribbons for Advanced Lithium-Sulfur Batteries, Advanced Energy Materials. 9 (2019) 1803137. doi:10.1002/aenm.201803137.

[21] P. Agarwal, I. Paramasivam, N.K. Shrestha, P. Schmuki, MoO3 in Self-Organized TiO2 Nanotubes for Enhanced Photocatalytic Activity, Chemistry-An Asian Journal. 5 (2010) 66-69.

[22] H. Zhou, X. Zou, K. Zhang, P. Sun, M.S. Islam, J. Gong, Y. Zhang, J. Yang, Molybdenum-Tungsten Mixed Oxide Deposited into Titanium Dioxide Nanotube Arrays for Ultrahigh Rate Supercapacitors, ACS Applied Materials \& Interfaces. 9 (2017) 1869918709.

[23] L.-Q. Mai, F. Yang, Y.-L. Zhao, X. Xu, L. Xu, Y.-Z. Luo, Hierarchical $\mathrm{MnMoO} 4 / \mathrm{CoMoO} 4$ heterostructured nanowires with enhanced supercapacitor performance, Nature Communications. 2 (2011) 381. doi:10.1038/ncomms1387.

[24] Y. Wu, Y. Yang, X. Zhao, Y. Tan, Y. Liu, Z. Wang, F. Ran, A Novel Hierarchical Porous 3D Structured Vanadium Nitride/Carbon Membranes for High-performance Supercapacitor Negative Electrodes, Nano-Micro Letters. 10 (2018) 63. doi:10.1007/s40820-018-0217-1.

[25] J.F. Callejas, C.G. Read, C.W. Roske, N.S. Lewis, R.E. Schaak, Synthesis, Characterization, and Properties of Metal Phosphide Catalysts for the Hydrogen-Evolution Reaction, Chemistry of Materials. 28 (2016) 6017-6044. doi:10.1021/acs.chemmater.6b02148.

[26] J.M. McEnaney, J.C. Crompton, J.F. Callejas, E.J. Popczun, A.J. Biacchi, N.S. Lewis, R.E. Schaak, Amorphous Molybdenum Phosphide Nanoparticles for Electrocatalytic Hydrogen Evolution, Chemistry of Materials. 26 (2014) 4826-4831. doi:10.1021/cm502035s.

[27] X. Li, A.M. Elshahawy, C. Guan, J. Wang, Metal Phosphides and Phosphates-based Electrodes for Electrochemical Supercapacitors, Small. 13 (2017) 1701530. doi:10.1002/smll.201701530.

[28] S.T. Oyama, Transition metal carbides, nitrides, and phosphides, Handbook of Heterogeneous Catalysis: Online. (2008) 342-356.

[29] S. Carenco, D. Portehault, C. Boissiere, N. Mezailles, C. Sanchez, Nanoscaled metal borides and phosphides: recent developments and perspectives, Chemical Reviews. 113 (2013) 7981-8065.

[30] X. Hu, W. Zhang, X. Liu, Y. Mei, Y. Huang, Nanostructured Mo-based electrode materials for electrochemical energy storage, Chemical Society Reviews. 44 (2015) 2376- 
2404. doi: $10.1039 / \mathrm{C} 4 \mathrm{CS} 00350 \mathrm{~K}$.

[31] G. Saeed, S. Kumar, N.H. Kim, J.H. Lee, Fabrication of 3D graphene-CNTs/ $\alpha-M o O 3$ hybrid film as an advance electrode material for asymmetric supercapacitor with excellent energy density and cycling life, Chemical Engineering Journal. 352 (2018) 268-276.

[32] J. Kibsgaard, T.F. Jaramillo, Molybdenum Phosphosulfide: An Active, Acid-Stable, Earth-Abundant Catalyst for the Hydrogen Evolution Reaction, Angewandte Chemie International Edition. 53 (2014) 14433-14437. doi:10.1002/anie.201408222.

[33] Y. Teng, X.-D. Wang, H.-Y. Chen, J.-F. Liao, W.-G. Li, D.-B. Kuang, Iron-assisted engineering of molybdenum phosphide nanowires on carbon cloth for efficient hydrogen evolution in a wide pH range, Journal of Materials Chemistry A. 5 (2017) 22790-22796. doi:10.1039/C7TA07895A.

[34] T. Wang, K. Du, W. Liu, Z. Zhu, Y. Shao, M. Li, Enhanced electrocatalytic activity of MoP microparticles for hydrogen evolution by grinding and electrochemical activation, Journal of Materials Chemistry A. 3 (2015) 4368-4373. doi:10.1039/C4TA06651K.

[35] B. Jin, X. Zhou, L. Huang, M. Licklederer, M. Yang, P. Schmuki, Aligned MoO x /MoS 2 Core-Shell Nanotubular Structures with a High Density of Reactive Sites Based on SelfOrdered Anodic Molybdenum Oxide Nanotubes, Angewandte Chemie International Edition. 55 (2016) 12252-12256. doi:10.1002/anie.201605551.

[36] D.J. Rensel, S. Rouvimov, M.E. Gin, J.C. Hicks, Highly selective bimetallic FeMoP catalyst for C-O bond cleavage of aryl ethers, Journal of Catalysis. 305 (2013) 256-263.

[37] W. Tang, C.X. Peng, C.T. Nai, J. Su, Y.P. Liu, M.V.V. Reddy, M. Lin, K.P. Loh, Ultrahigh Capacity Due to Multi-Electron Conversion Reaction in Reduced Graphene Oxide-Wrapped MoO2 Porous Nanobelts, Small. 11 (2015) 2446-2453.

[38] M. Shimoda, T. Hirata, K. Yagisawa, M. Okochi, A. Yoshikawa, Deconvolution of Mo 3d $\mathrm{X}$-ray photoemission spectray-Mo $4 \mathrm{O}$ 11: Agreement with prediction from bond lengthbond strength relationships, Journal of Materials Science Letters. 8 (1989) 1089-1091.

[39] Z. Yao, Y. Su, C. Lu, C. Yang, Z. Xu, J. Zhu, X. Zhuang, F. Zhang, Template-directed approach to two-dimensional molybdenum phosphide-carbon nanocomposites with high catalytic activities in the hydrogen evolution reaction, New Journal of Chemistry. 40 (2016) 6015-6021.

[40] P. Xiao, M.A. Sk, L. Thia, X. Ge, R.J. Lim, J.-Y. Wang, K.H. Lim, X. Wang, Molybdenum phosphide as an efficient electrocatalyst for the hydrogen evolution reaction, Energy \& Environmental Science. 7 (2014) 2624-2629.

[41] Z. Xing, Q. Liu, A.M. Asiri, X. Sun, Closely interconnected network of molybdenum phosphide nanoparticles: a highly efficient electrocatalyst for generating hydrogen from water, Advanced Materials. 26 (2014) 5702-5707.

[42] E. Kayali, A. VahidMohammadi, J. Orangi, M. Beidaghi, Controlling the Dimensions of 2D MXenes for Ultrahigh-Rate Pseudocapacitive Energy Storage, ACS Applied Materials \& Interfaces. 10 (2018) 25949-25954.

[43] L. Qin, Q. Tao, A. El Ghazaly, J. Fernandez-Rodriguez, P.O.Å. Persson, J. Rosen, F. Zhang, High-Performance Ultrathin Flexible Solid-State Supercapacitors Based on Solution Processable Mo 1.33 C MXene and PEDOT:PSS, Advanced Functional Materials. 28 (2018) 1703808. doi:10.1002/adfm.201703808.

[44] S. Ozkan, N.T. Nguyen, I. Hwang, A. Mazare, P. Schmuki, Highly conducting spaced $\mathrm{TiO} 2$ nanotubes enable defined conformal coating with nanocrystalline $\mathrm{Nb} 2 \mathrm{O} 5$ and high performance supercapacitor applications, Small. 13 (2017) 1603821. 
[45] M. Yu, Y. Han, X. Cheng, L. Hu, Y. Zeng, M. Chen, F. Cheng, X. Lu, Y. Tong, Holey Tungsten Oxynitride Nanowires: Novel Anodes Efficiently Integrate Microbial Chemical Energy Conversion and Electrochemical Energy Storage, Advanced Materials. 27 (2015) 3085-3091. doi:10.1002/adma.201500493.

[46] J. Wang, J. Polleux, J. Lim, B. Dunn, Pseudocapacitive contributions to electrochemical energy storage in TiO2 (anatase) nanoparticles, The Journal of Physical Chemistry C. 111 (2007) 14925-14931.

[47] V. Augustyn, J. Come, M.A. Lowe, J.W. Kim, P.-L. Taberna, S.H. Tolbert, H.D. Abruña, P. Simon, B. Dunn, High-rate electrochemical energy storage through Li+ intercalation pseudocapacitance, Nature Materials. 12 (2013) 518-522. doi:10.1038/nmat3601.

[48] P. Simon, Y. Gogotsi, B. Dunn, Where do batteries end and supercapacitors begin?, Science. 343 (2014) 1210-1211.

[49] Y. Yang, H. Fei, G. Ruan, C. Xiang, J.M. Tour, Edge-Oriented MoS2 Nanoporous Films as Flexible Electrodes for Hydrogen Evolution Reactions and Supercapacitor Devices, Advanced Materials. 26 (2014) 8163-8168. 
Figure 1 Structural and crystallographic characterization: (a) top view SEM image of as-formed Mo oxide nanotube layer; (b) XRD patterns of structures crystallized and phosphidized under different conditions; (c) top view SEM image of MoP-protected structures $\left(300^{\circ} \mathrm{C}\right)$; Insets in (a) and (c): cross sectional SEM and optical images of Mo oxide and MoP-protected NT layers; (d) and (e) HR-TEM images of $\mathrm{Mo}_{4} \mathrm{O}_{11}$ and $\mathrm{MoP}-\mathrm{MoO}_{x}$ nanotubes (phosphidized at $300^{\circ} \mathrm{C}$ ), respectively: Insets in (d) and (e): TEM images of individual $\mathrm{Mo}_{4} \mathrm{O}_{11}$ and $\mathrm{MoP}-\mathrm{MoO}_{\mathrm{x}}$ nanotubes; $(\mathrm{f})$ and $(\mathrm{g})$ SAED pattern of $\mathrm{Mo}_{4} \mathrm{O}_{11}$ and $\mathrm{MoP}-\mathrm{MoO}_{x}$ nanotubes (phosphidized at $300^{\circ} \mathrm{C}$ ), respectively; (h-k) EDS-Mapping of MoP-MoO $x$ nanotubes (phosphidized at $300^{\circ} \mathrm{C}$ ) showing the (h) TEM image and the (i) Mo, (j) P, and $(\mathrm{k}) \mathrm{O}$ distribution. 

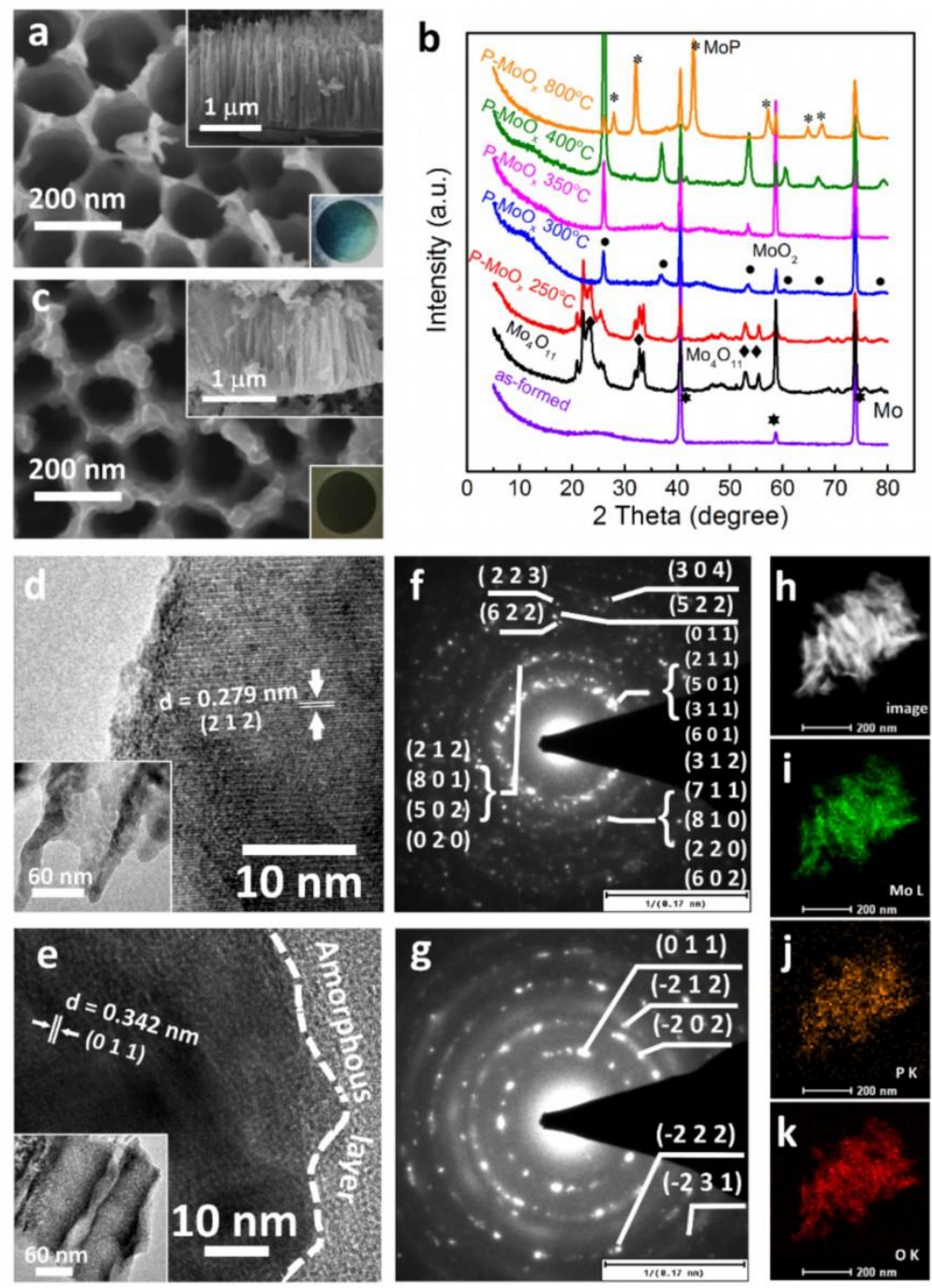
Figure 2 Composition characterization: (a) and (b) high revolution (a) Mo3d and (b) P2p XPS spectra of a $1.3 \mu \mathrm{m}$-thick MoP-MoO nanotube layer (phosphidized at $300^{\circ} \mathrm{C}$ ); (c) XPS depth profiles of a MoP-protected Mo oxide nanotube layer (phosphidized at $300^{\circ} \mathrm{C}$ ).

a

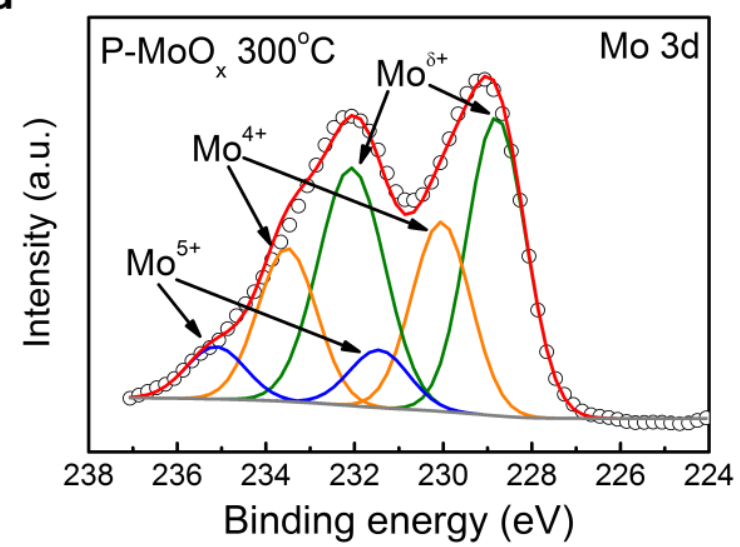

b

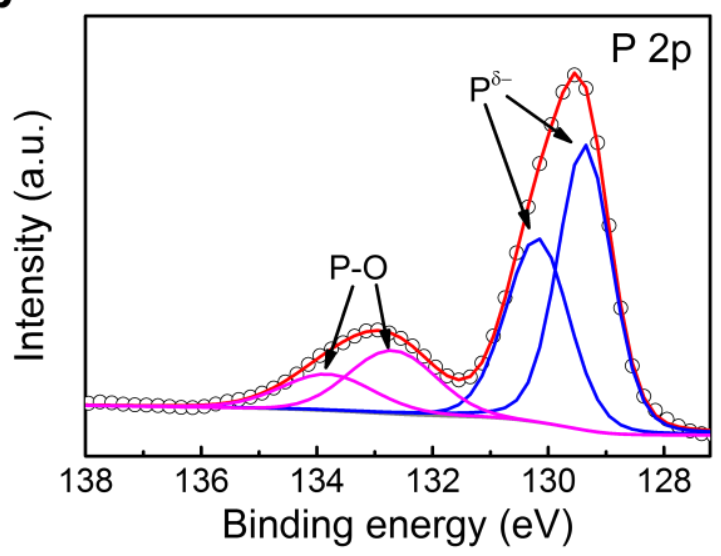

C

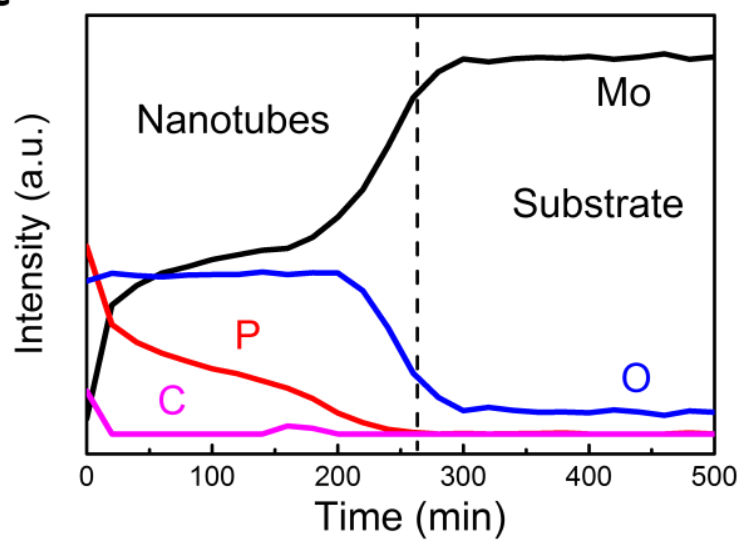


Figure 3 Electrochemical performance of $1.3 \mu$ m-thick NT electrode: (a) GCD profiles of MoP-MoOx nanotubes (protected by phosphidation at $300^{\circ} \mathrm{C}$ ) recorded at different current rates $\left(1-100 \mathrm{~A} \mathrm{~cm}^{-}\right.$ ${ }^{3}$ ); (b) GCD profiles recorded at $1 \mathrm{~A} \mathrm{~cm}^{-3}$ for structures crystallized and MoP-protected at different temperatures; (c) Volumetric capacitances recorded at different current rates $\left(1-100 \mathrm{~A} \mathrm{~cm}^{-3}\right)$ for structures crystallized and MoP-protected at different temperatures; (d) EIS data (Nyquist plots) recorded for structures crystallized and MoP-protected at different temperatures; Inset in (d) high frequency range.

a

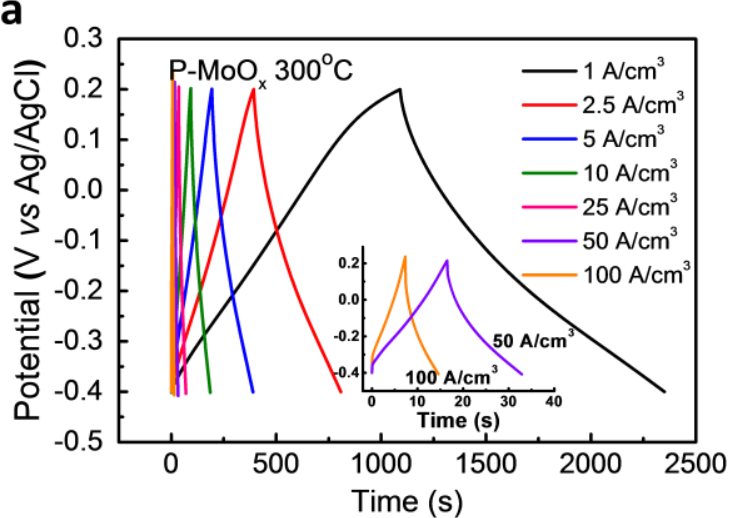

C

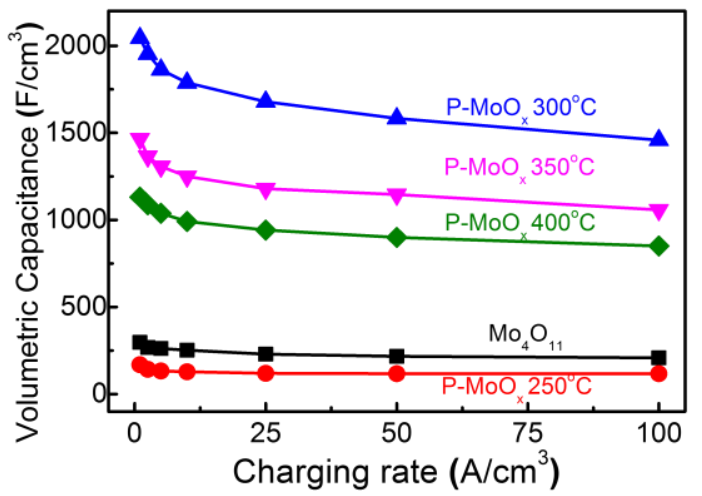

b

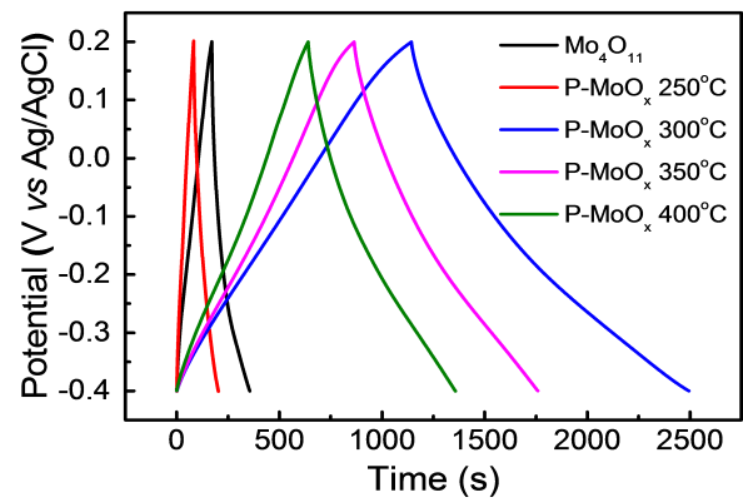

d

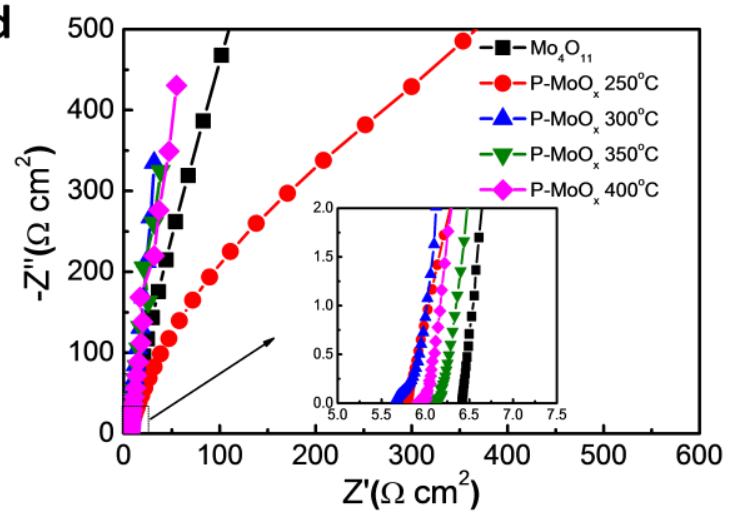


Figure 4 Electrochemical performance: (a) CV profiles recorded at different scan rates (10-200 mV $\mathrm{s}^{-1}$ ) for $\mathrm{MoP}-\mathrm{MoO}_{\mathrm{x}}$ nanotubes (MoP-protected by phosphidation at $300^{\circ} \mathrm{C}$ ); (b) volumetric capacitances recorded at different scan rates for structures crystallized and MoP-protected at different temperatures; (c) capacitance retention tests performed for $\mathrm{MoO}_{3}$ and $\mathrm{MoP}-\mathrm{MoO}_{x}$ nanotubes (MoP-protected at $300^{\circ} \mathrm{C}$ ) at $100 \mathrm{mV} \mathrm{s}^{-1}$ over $10^{\prime} 000$ consecutive $\mathrm{CV}$ cycles; (d) CV profiles collected at 2 and $10 \mathrm{mV} \mathrm{s}^{-1}$ with $\mathrm{MoP}-\mathrm{MoO}_{x}$ nanotubes (MoP-protected at $300^{\circ} \mathrm{C}$ ); the hatched area in the CV profiles in (d) define the electrochemical capacitance contribution not limited by diffusion (" $\mathrm{C}-$ "), and vertical lines limit the $\mathrm{CV}$ area taken into account for calculations.
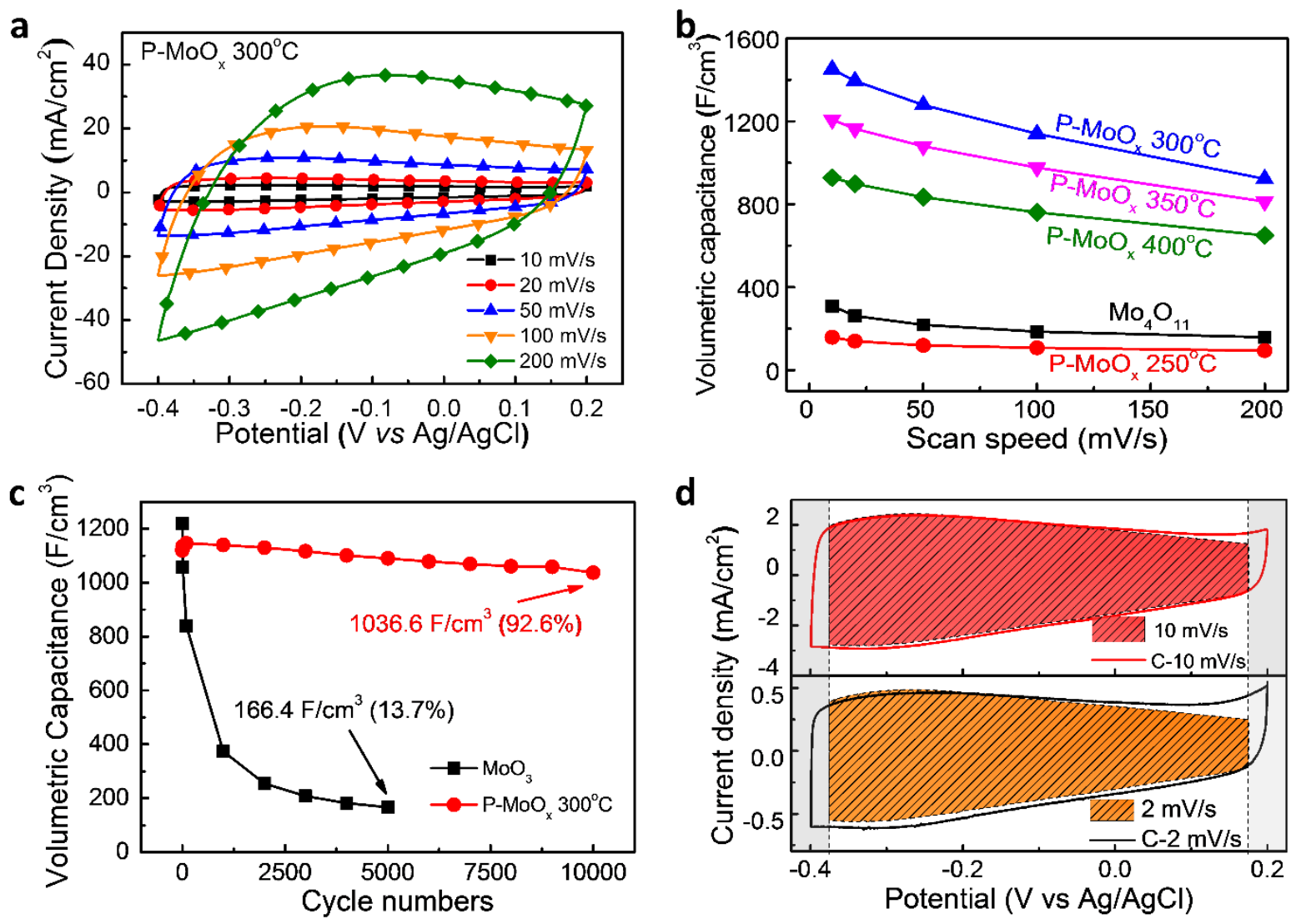


\section{MoP-protected Mo oxide nanotube arrays for long-term stable supercapacitors}

Bowen Jin, ${ }^{a, b}$ Seyedsina Hejazi, ${ }^{b}$ Hongqi Chu, ${ }^{a}$ Shiva Mohajernia, ${ }^{b}$ Nhat Truong Nguyen,${ }^{b}$ Min Yang, ${ }^{a *}$ Marco Altomare, ${ }^{b *}$ and Patrik Schmuki ${ }^{b, c *}$

${ }^{a}$ MIIT Key Laboratory of Critical Materials Technology for New Energy Conversion and Storage, School of Chemistry and Chemical Engineering, Harbin Institute of Technology, Harbin, 150001, PR China.

b Department of Materials Science, Institute for Surface Science and Corrosion WW4-LKO, University of Erlangen-Nuremberg, Martensstrasse 7, 91058 Erlangen, Germany.

${ }^{c}$ Chemistry Department, Faculty of Sciences, King Abdulaziz University, 80203 Jeddah, Saudi Arabia Kingdom

Corresponding authors: E-mail: $\quad$ yangmin@hit.edu.cn marco.altomare@fau.de schmuki@ww.uni-erlangen.de 


\section{Optimization of oxide NT crystallization}

Prior to MoP-protection (phosphidation), amorphous oxide NTs can be converted into $\alpha \mathrm{MoO}_{3}$ (Mo(VI); JCPDS Card No. 05-0508) by annealing in air $\left(350^{\circ} \mathrm{C}\right)$. On the other hand, a thermal treatment in vacuum at $350^{\circ} \mathrm{C}$ leads to NT structures composed of a sub-stoichiometric $\mathrm{Mo}_{4} \mathrm{O}_{11}$ cubic phase (Mo(VI) and Mo(V); JCPDS Card No. 73-1538) (Fig. S2g). Annealing in vacuum was selected for further work as layers pretreated under these conditions were found to be the most suitable for the subsequent MoP-protection (phosphidation) step, and led to superior electrochemical cycling stability and performance (discussed in the main text; data in Fig. S4).

\section{Optimization of NT protection (phosphidation)}

The Mo oxide NT layers were treated by phosphidation to form a MoP surface protection shell. Tunable crystalline phase and chemical composition were achieved by adjusting the phosphidation temperature (data in Fig. 1, Fig. 2, Table S1 and Table S2):

- At $250^{\circ} \mathrm{C}$ the NT crystallographic composition is virtually unaltered compared to vacuum annealed layers; these layers are still composed of $\mathrm{Mo}_{4} \mathrm{O}_{11}(\mathrm{Mo}(\mathrm{VI})$ and $\mathrm{Mo}(\mathrm{V}))$. EDS analysis shows a relatively low phosphorus content $(\sim 1.8$ at $\%)$.

- At $300^{\circ} \mathrm{C}$ the NTs are fully converted into monoclinic $\mathrm{MoO}_{2}$ phase (Mo(IV); JCPDS Card No. 47-0124) at the expenses of $\mathrm{Mo}_{4} \mathrm{O}_{11}$ phase. While no MoP XRD reflections can be seen, EDS analysis reveals an increased P content up to $~ 30$ at $\%$. SEM and optical images of a MoP-protected (phosphidized) $\mathrm{MoO}_{2}$ NT layer are shown in Fig. 1c. An evident layer color change can be appreciated with the unaided eye (Fig. 1c, optical image). In spite of the remarkable changes in chemical composition, only minor morphological modifications take place at the nanoscale; 
- With increasing the phosphidation temperature up to $700^{\circ} \mathrm{C}$, neither significant changes are seen, nor do characteristic XRD reflections of MoP appear. Nevertheless, the content of $\mathrm{MoO}_{2}$ phase noticeably increases, the $\mathrm{P}$ content remains relatively high (above 25 at\%), while the oxygen content gradually decreases (from $\sim 48$ to $\sim 27$ at $\%$ );

- At $800^{\circ} \mathrm{C}$, i.e. above the MoP glass transition temperature $\left(\geq 700^{\circ} \mathrm{C}^{1}\right)$, the $\mathrm{MoO}_{2} \mathrm{NTs}$ are to a large extent transformed into hexagonal (P-6m2) MoP phase (Mo(III); JCPDS Card No. 240771) without undergoing structural deterioration (Fig. S2f). The oxygen signal is still detectable in these structures although present in significantly lower concentration ( 27 at\%), in line with the weak XRD reflections from $\mathrm{MoO}_{2}$. A reasonable assumption is that a longer phosphidation treatment at such temperature would lead to a full conversion of the $\mathrm{MoO}_{2} \mathrm{NTs}$ into crystalline MoP phase.

The XPS data in Fig. S3 (along with data in Fig. 2a) outline the evolution of the Mo chemical surrounding with various thermal treatments:

- For the reference oxide structures $\left(350^{\circ} \mathrm{C}\right.$, in vacuum), the Mo3p signal can be assigned to $\mathrm{Mo}(\mathrm{VI})$ and $\mathrm{Mo}(\mathrm{V})$ oxide species, in line with a $\mathrm{Mo}_{4} \mathrm{O}_{11}$ cubic phase composition;

- When phosphidation is carried out at $250^{\circ} \mathrm{C}$, the Mo signal can still be attributed mainly to $\mathrm{Mo}(\mathrm{VI})$ and $\mathrm{Mo}(\mathrm{V})$ oxide species (i.e. $\mathrm{Mo}_{4} \mathrm{O}_{11}$ phase). However, a peak at lower B.E. values $(\sim 228.7 \mathrm{eV})$ appears, which suggests that phosphidation is incipient. Accordingly, EDS data show a P content of $\sim 1.8$ at $\%$;

- For phosphidation temperatures $\geq 300^{\circ} \mathrm{C}$, the NT surface is mainly composed of MoP, and the higher the temperature the larger the $\mathrm{MoP}$ content. We observed that $\mathrm{MoP}$ forms stepwise at the expenses of $\mathrm{Mo}(\mathrm{V})$ and $\mathrm{Mo}(\mathrm{IV})$ oxides. Note in fact that EDS analysis reveals an increase of the P content, while oxygen diminishes (see Table S1 and S2). For phosphidation 
temperatures $\geq 350^{\circ} \mathrm{C}$, a relatively small signal appears at low B.E. values $(\sim 227.4 \mathrm{eV})$ that can be attributed to $\mathrm{Mo}^{0}$. 
Figure S1 (a-d) top view SEM image of as-formed Mo oxide nanotube layers grown at different anodization voltages: (a) $20 \mathrm{~V}$; (b) $30 \mathrm{~V}$; (c) $40 \mathrm{~V}$; (d) $60 \mathrm{~V}$. Insets in (a-c): relative cross sectional SEM and optical images; (e) diameter and length of the Mo oxide nanotubes as a function of the anodization voltage.
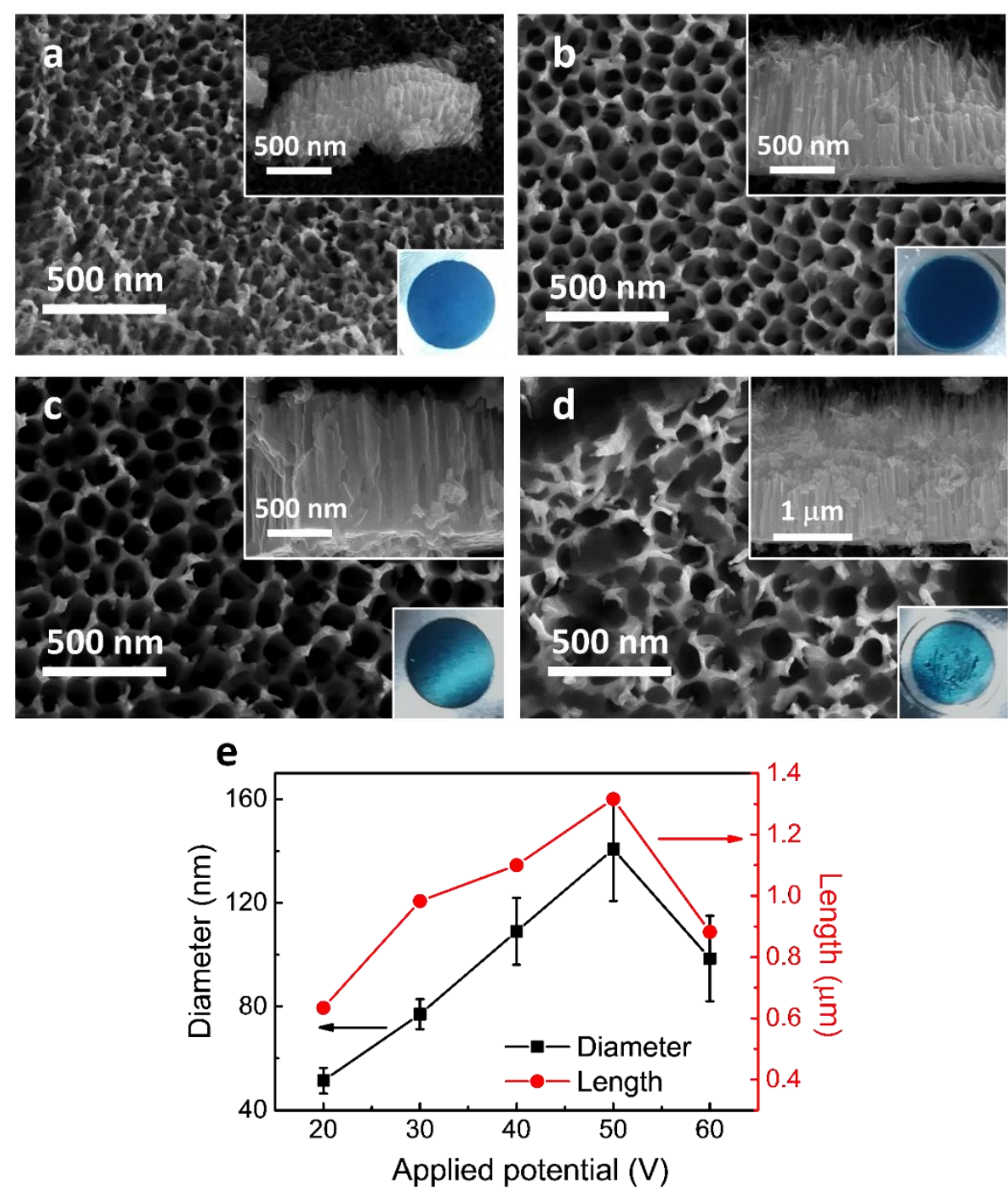
Figure S2 SEM images of NTs crystallized and MoP-protected at different temperatures: (a) $\mathrm{Mo}_{4} \mathrm{O}_{11}$ NTs, i.e. crystallized in vacuum at $350^{\circ} \mathrm{C}$; (b) $\mathrm{MoO}_{3} \mathrm{NTs}$, i.e. crystallized in air at $350^{\circ} \mathrm{C}$; (c-e) MoPprotected $\mathrm{MoO}_{x} \mathrm{NTs}$ phosphidized at (c) $250^{\circ} \mathrm{C}$; (d) $350^{\circ} \mathrm{C}$ and (e) $400^{\circ} \mathrm{C}$; (f) MoP NTs formed at $800^{\circ} \mathrm{C}$; (g) XRD patterns of Mo oxide NTs crystallized in air or vacuum at $350^{\circ} \mathrm{C}$.

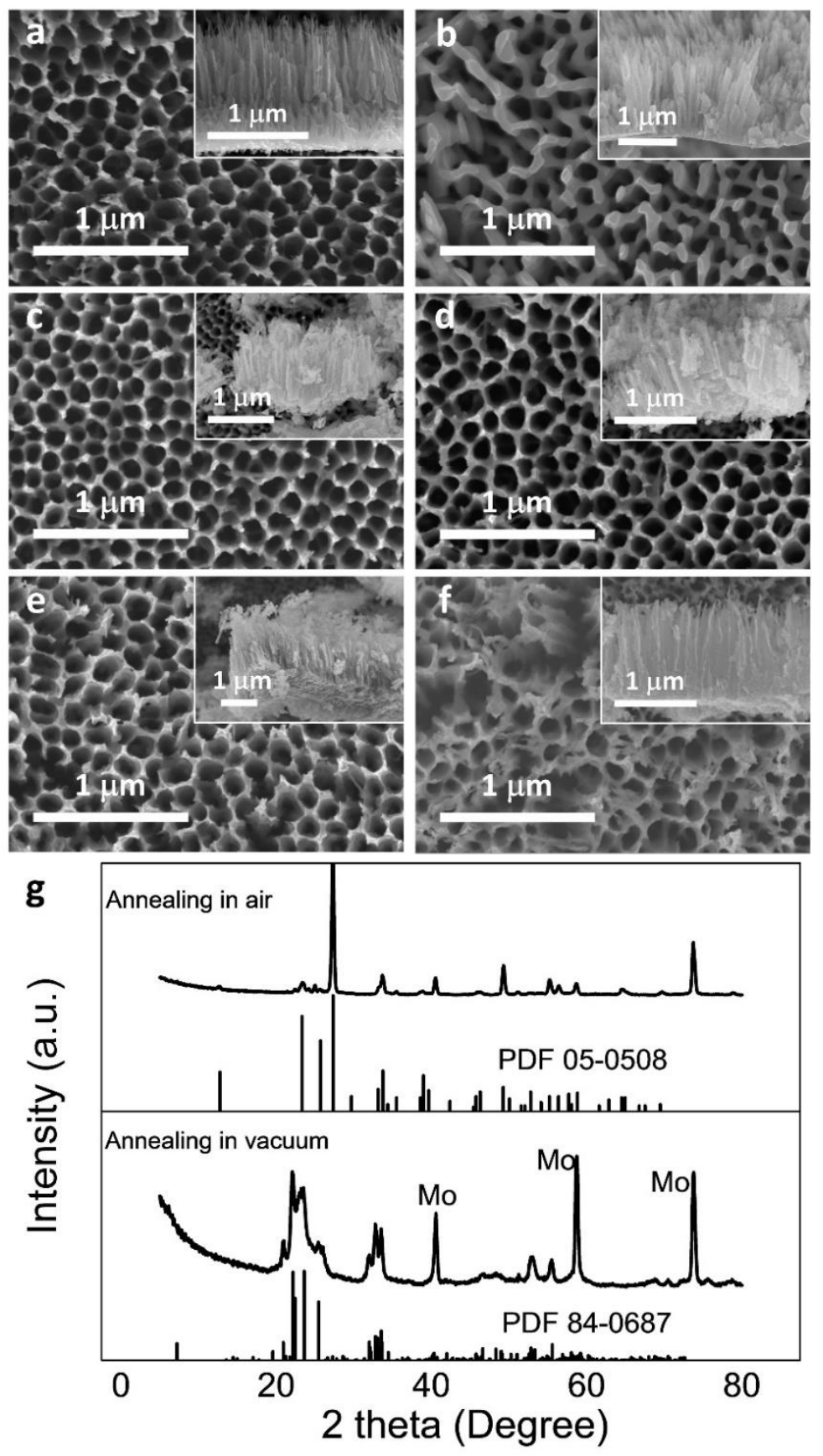


Figure S3 High revolution Mo3d XPS spectra of structures crystallized and MoP-protected at different phosphidation temperatures.

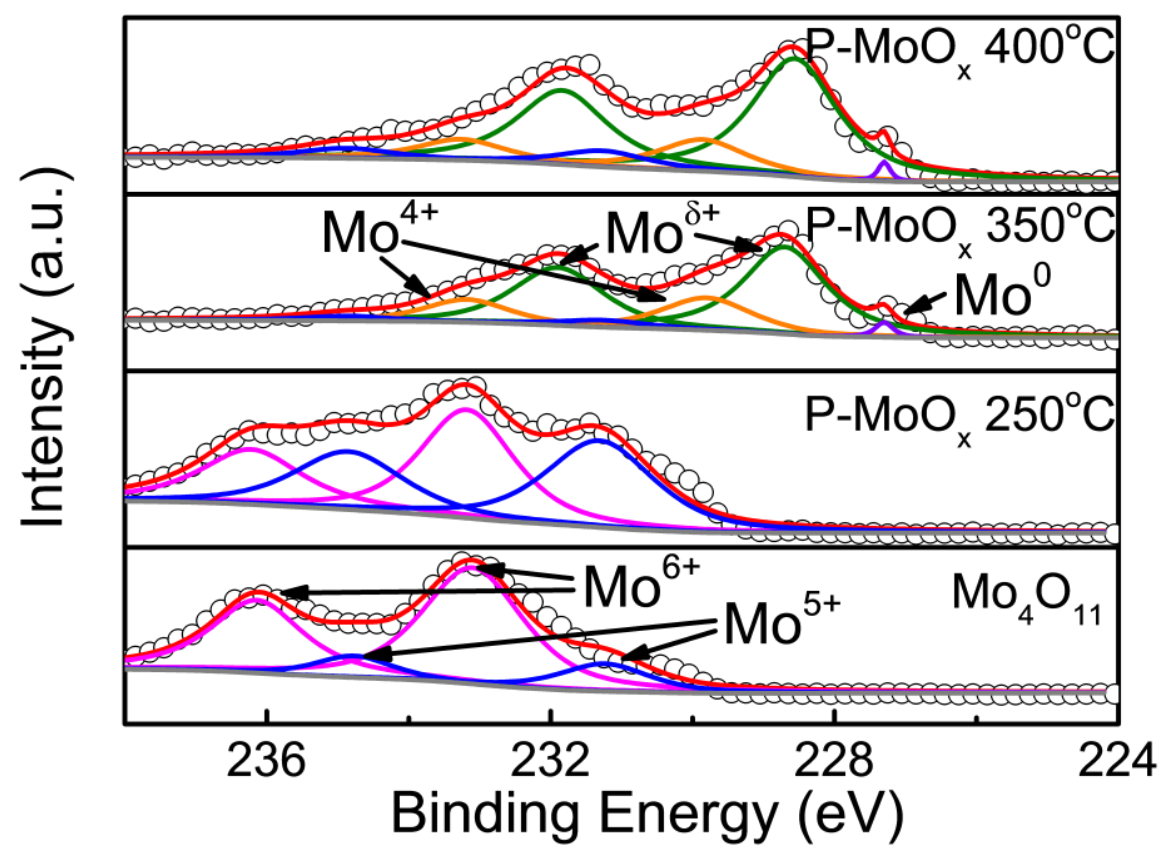


Figure S4 (a) The CV plots of $\mathrm{MoO}_{3}$ in 5000 cycles (b) The CV plots of $\mathrm{P}^{-\mathrm{MoO}_{\mathrm{x}}}$ in 10000 cycles.

a

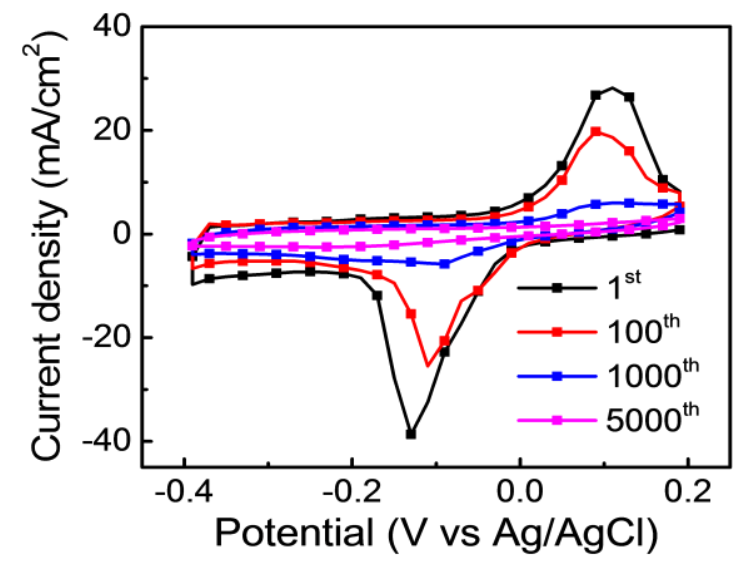

b

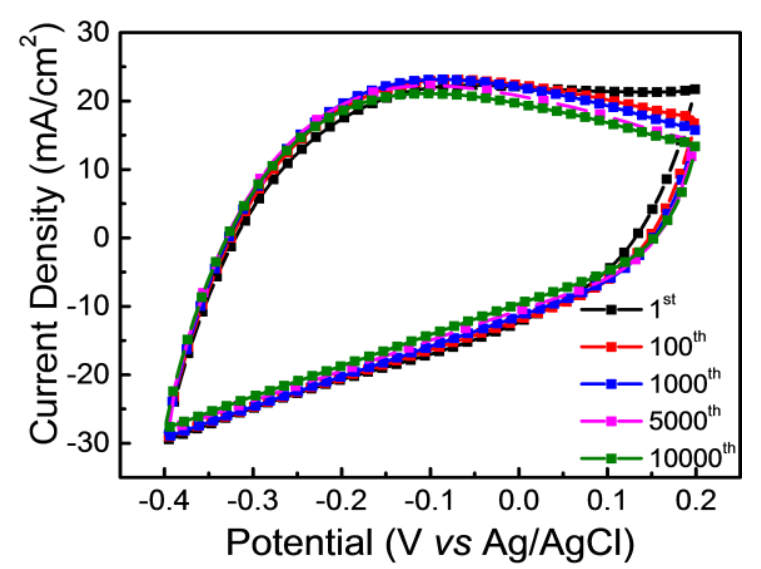

Figure $\mathrm{S} 5$ (a) CV profiles recorded in $1 \mathrm{M} \mathrm{H}_{2} \mathrm{SO}_{4}$ at a scan rate of $5 \mathrm{mV} \mathrm{s}^{-1}$ in the $-0.6-0.2 \mathrm{~V}$ potential range for $1.3 \mu \mathrm{m}$-thick vacuum-annealed Mo oxide NTs and MoP-protected Mo oxide NT electrodes; (b) CV profiles of MoP-MoOx NTs recorded in different potential windows.
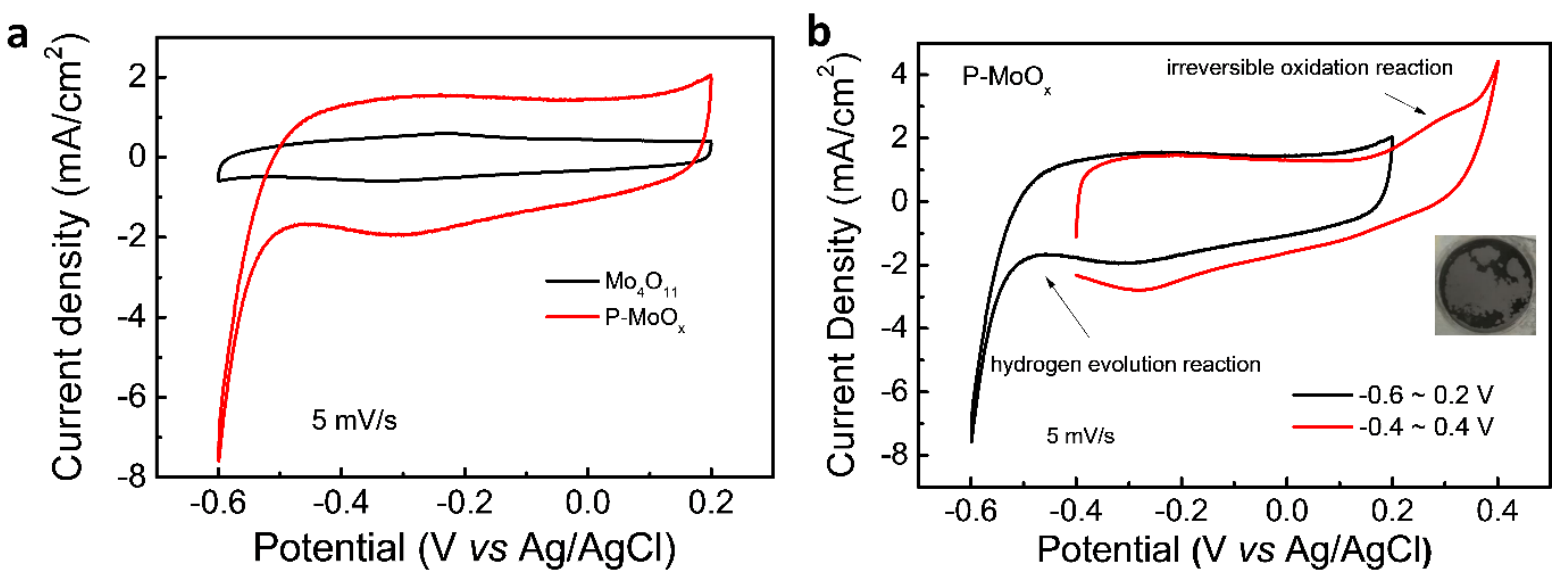
Figure S6 Electrochemical performance of $\mathrm{Mo}_{4} \mathrm{O}_{11} \mathrm{NTs}$, i.e. crystallized in vacuum at $350^{\circ} \mathrm{C}$ : (a) CV profiles recorded $1 \mathrm{M} \mathrm{H}_{2} \mathrm{SO}_{4}$ at a scan rate of $100 \mathrm{mV} \mathrm{s}^{-1}$; (b) volumetric capacitances recorded at different scan rates.
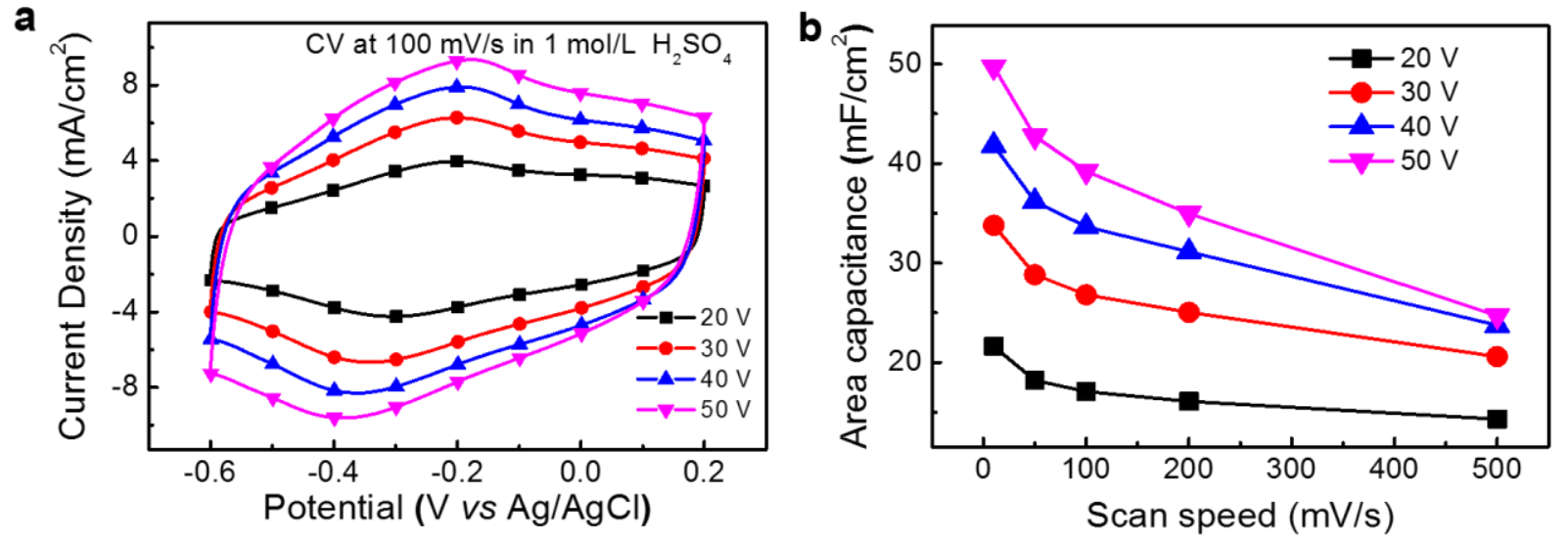

Figure S7 Electrochemical performance of Mo oxide NTs crystallized in air or in vacuum at $350^{\circ} \mathrm{C}$ and then MoP-protected at $300^{\circ} \mathrm{C}$ : (a) $\mathrm{CV}$ profiles recorded $1 \mathrm{M} \mathrm{H}_{2} \mathrm{SO}_{4}$ at a scan rate of $200 \mathrm{mV} \mathrm{s}^{-}$ 1; (b) volumetric capacitance recorded at different scan rates;
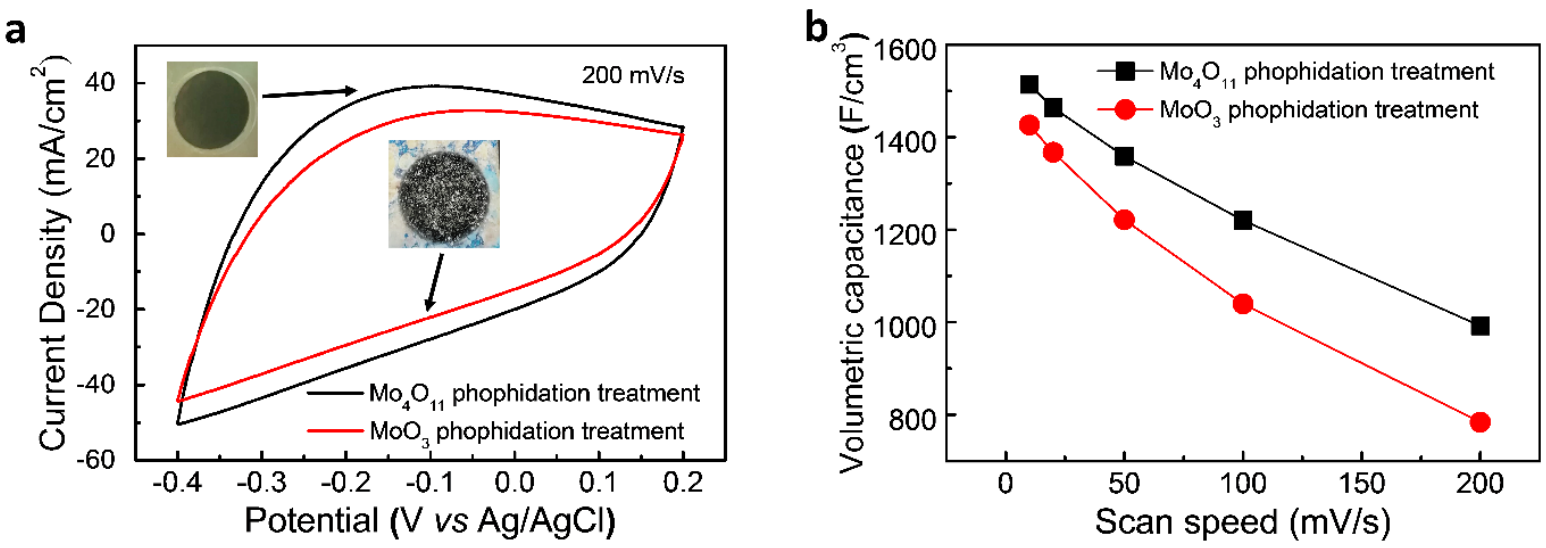
Figure S8 Galvanostatic charge-discharge (GCD) profiles collected at different current densities (1$100 \mathrm{~A} \mathrm{~cm}^{-3}$ range) in $1 \mathrm{M} \mathrm{H}_{2} \mathrm{SO}_{4}$ for $1.3 \mu \mathrm{m}$-thick NT structures crystallized and MoP-protected at different temperatures: (a) $\mathrm{Mo}_{4} \mathrm{O}_{11} \mathrm{NTs}$, i.e. crystallized in vacuum at $350^{\circ} \mathrm{C}$; (b-d) MoP-protected NTs phosphidized at different temperatures: (b) $250^{\circ} \mathrm{C}$; (c) $350^{\circ} \mathrm{C}$; (d) $400^{\circ} \mathrm{C}$.

a

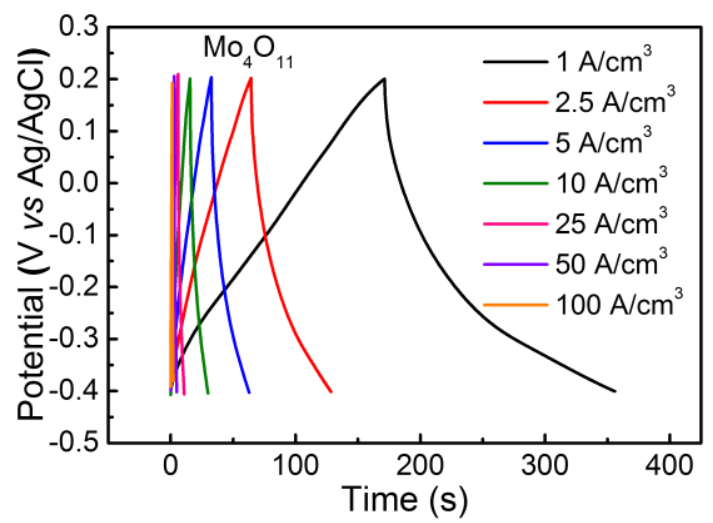

C

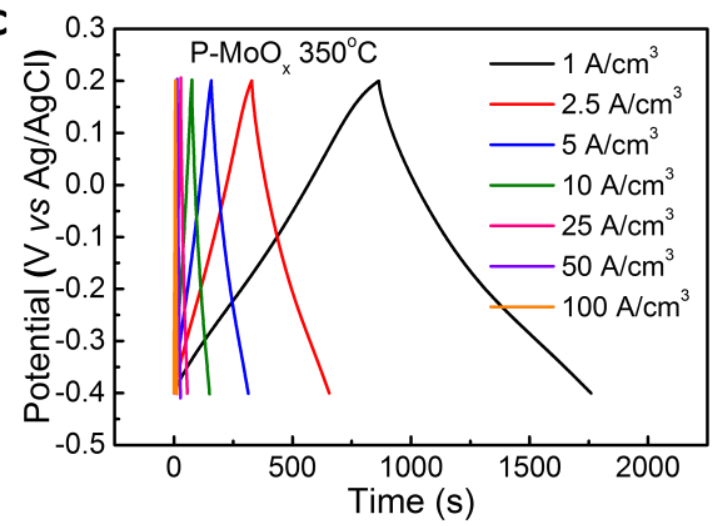

b

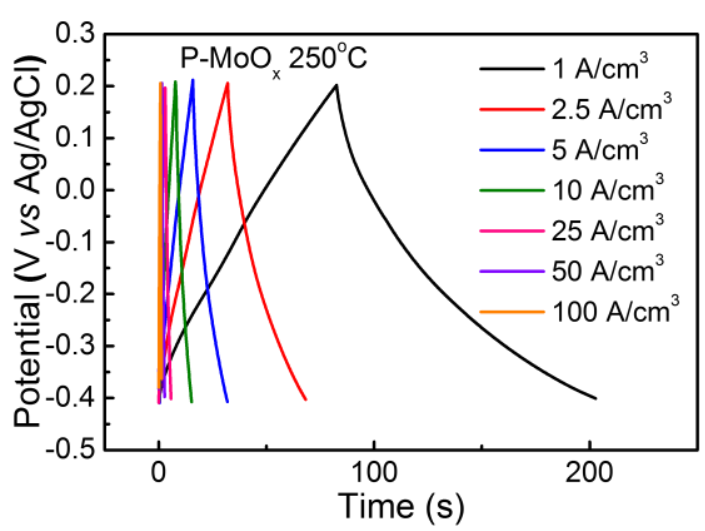

d

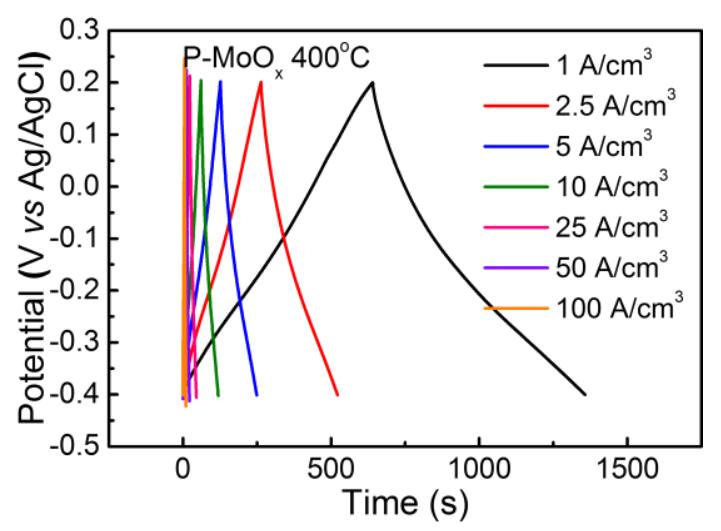


Figure S9 SEM image of a Mo metal substrate after removing the MoP-protected $\mathrm{MoO}_{x} \mathrm{NT}$ active layer (by cathodic polarization followed by ultrasonication); Inset: optical photograph.

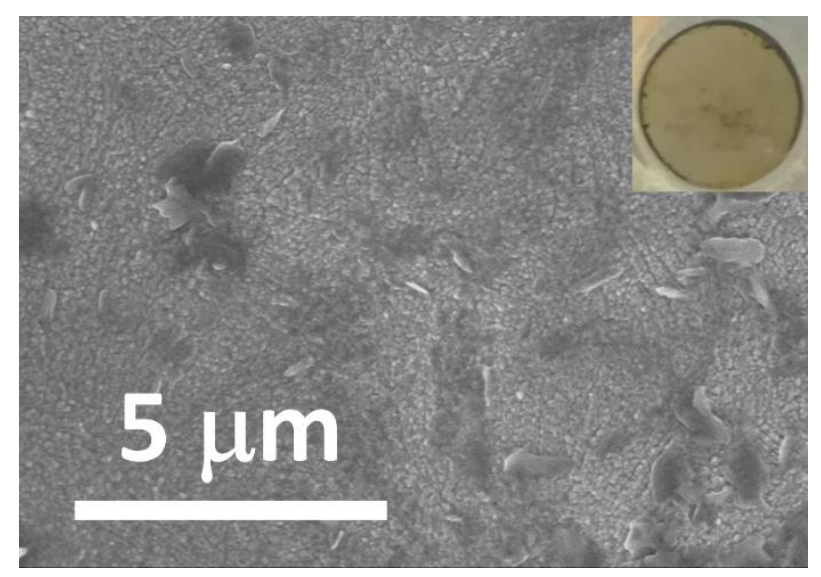

Figure S10 High-magnification cross-sectional SEM image of MoP-protected $\mathrm{MoO}_{x}$ NT layer; the overlaid plot (showing the correlation between the image grey value and the NT morphology) was used to calculate the active material volume.

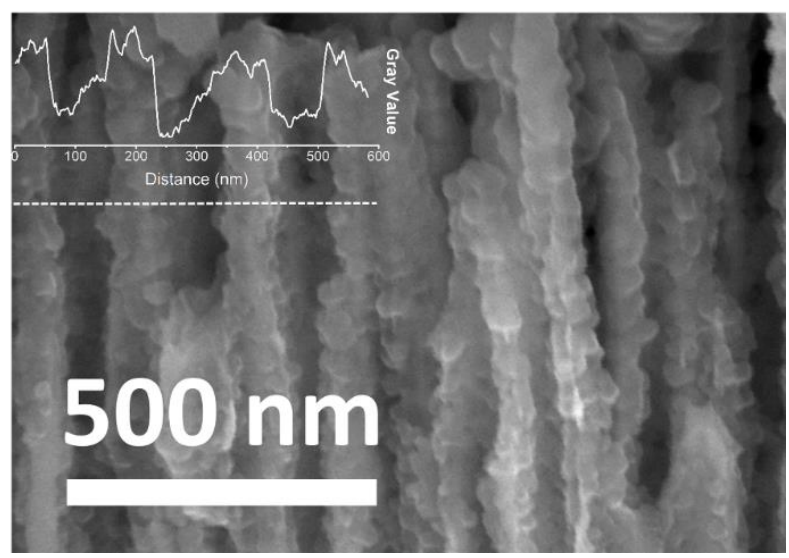


Figure S11 SEM and XRD characterization and electrochemistry performance of a nanoporous (reference) $\mathrm{MoO}_{x}$ electrode before and after MoP-protection. (a,b) SEM images of the electrode (a) before and (b) after phosphidation (insets: cross-sections); (c) XRD patterns; (d) comparison between the volumetric capacitance of MoP-MoO $\mathrm{NT}$ and nanoporous electrodes (inset: GCD plot of NT and nanoporous electrodes at $1 \mathrm{~A} / \mathrm{cm}^{3}$ ).

a

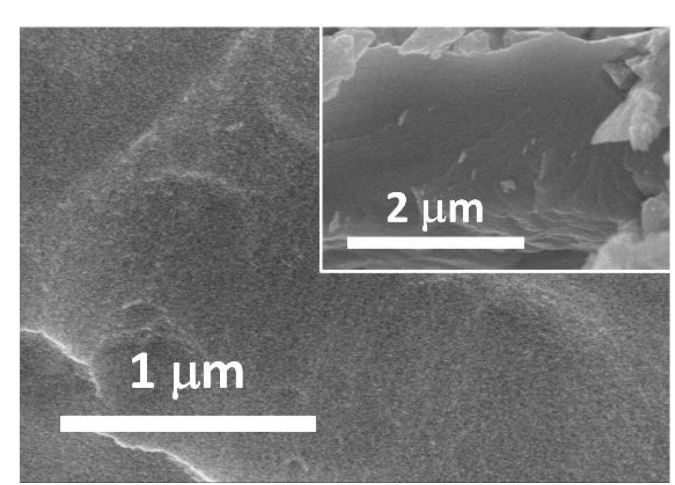

C

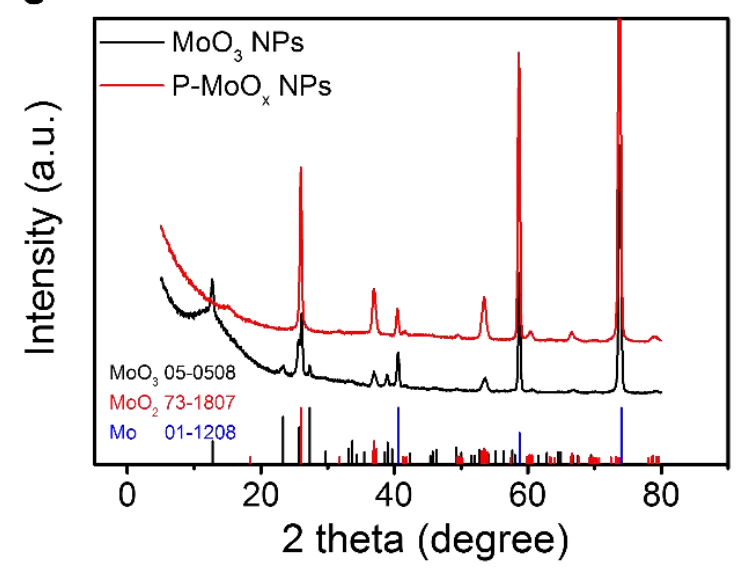

b

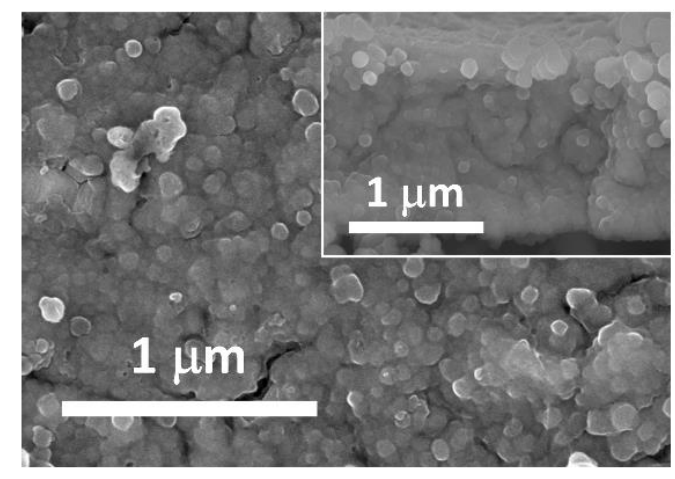

d

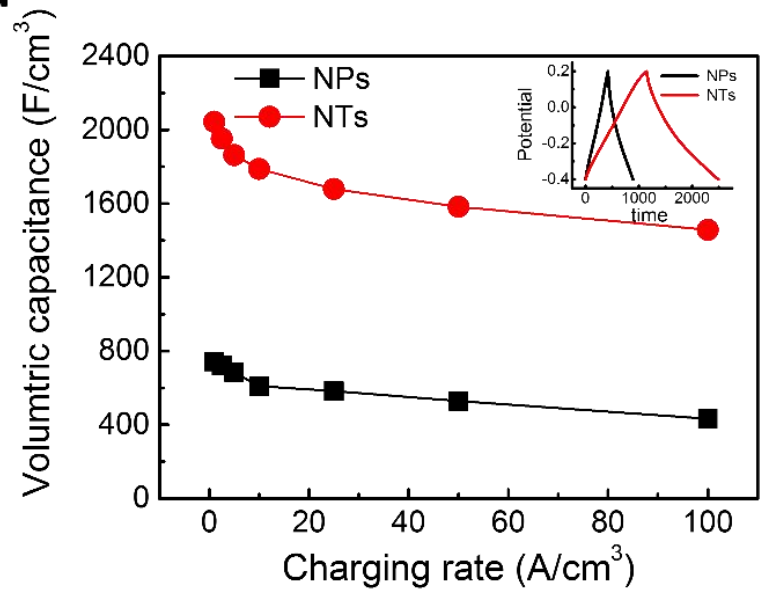


Figure S12 SEM characterization and electrochemistry performance of MoP-MoOx NTs of different thicknesses. (a,b) SEM images of (a) 0.65 and (b) $3.2 \mu$ m-thick NTs; c) GCD plot of MoP-MoOx NTs measured at $1 \mathrm{~A} / \mathrm{cm}^{3}$; (d) volumetric capacitance of MoP-MoOx NT electrodes of different thicknesses.

a

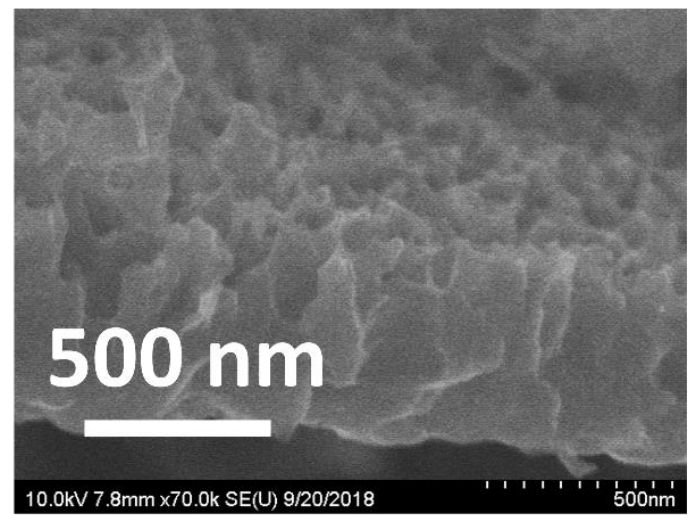

C

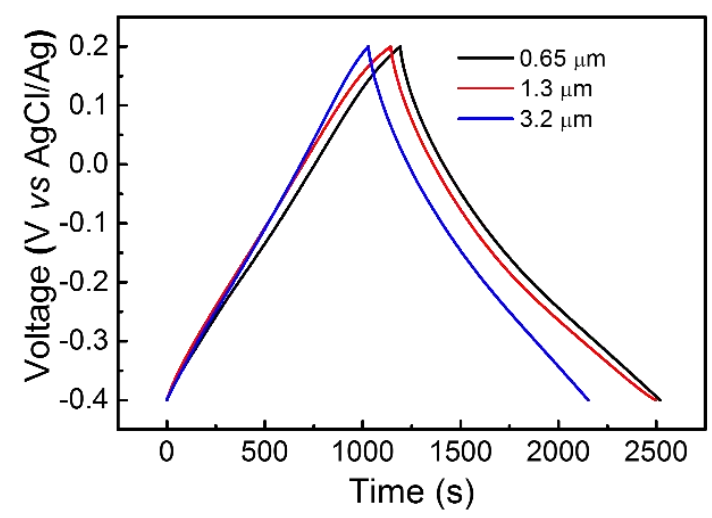

b

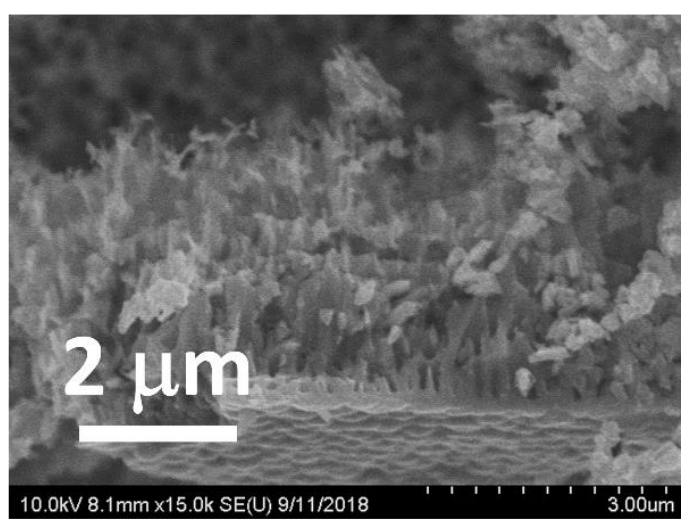

d

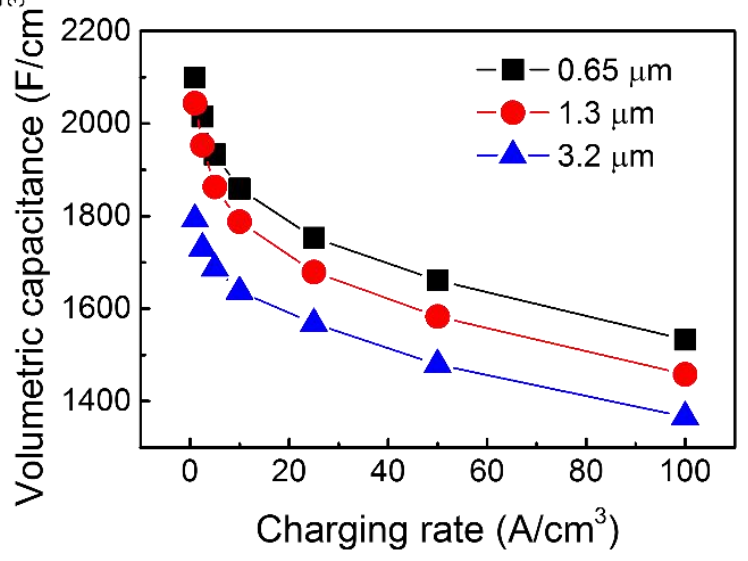


Figure S13 Bode plots for NT crystallized and MoP-protected at different phosphidation temperatures, measured from $10^{5}$ to $10^{-2} \mathrm{~Hz}$ in $1 \mathrm{M} \mathrm{H}_{2} \mathrm{SO}_{4}$.

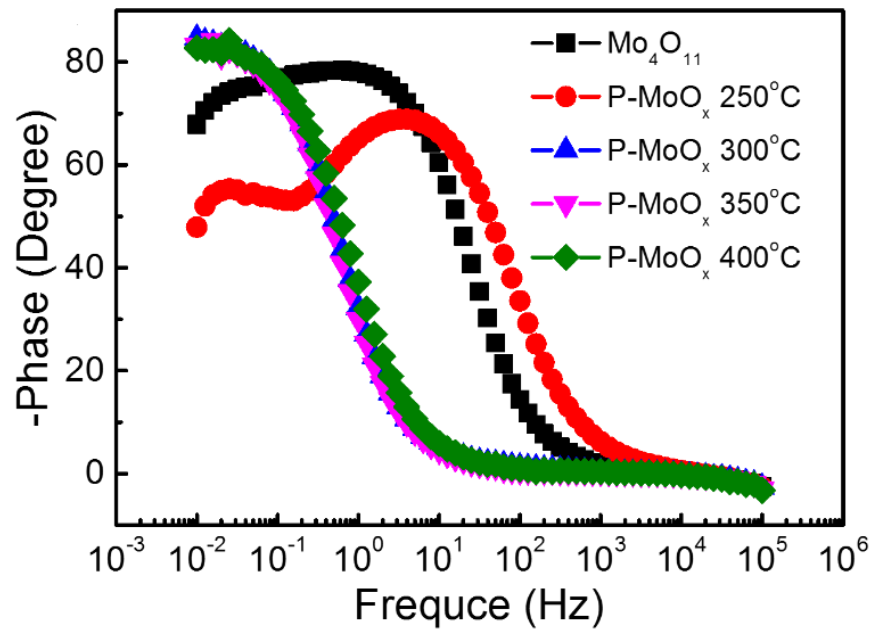

Figure S14 Dynamic contact angle results of $\mathrm{Mo}_{4} \mathrm{O}_{11} \mathrm{NTS}$, i.e. crystallized in vacuum at $350^{\circ} \mathrm{C}$, and of MoP-protected $\mathrm{MoO}_{x}$ NTs phosphidized at $300^{\circ} \mathrm{C}$.

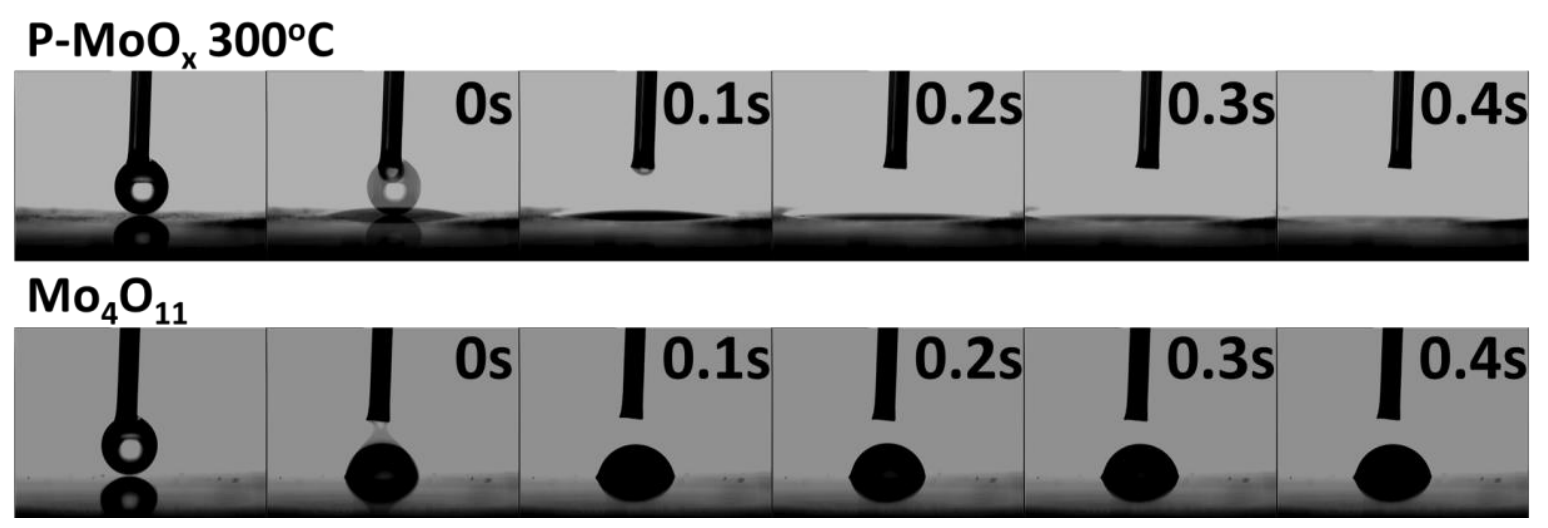


Figure S15 CV profiles collected at different scan rates (10-200 mV s${ }^{-1}$ range) in $1 \mathrm{M} \mathrm{H}_{2} \mathrm{SO}_{4}$ for NT structures crystallized and MoP-protected at different temperatures: (a) $\mathrm{Mo}_{4} \mathrm{O}_{11}$ NTs, i.e. crystallized in vacuum at $350^{\circ} \mathrm{C}$; (b-e) MoP-protected NTs phosphidized at different temperatures:

(b) $250^{\circ} \mathrm{C}$; (c) $350^{\circ} \mathrm{C}$; (d) $400^{\circ} \mathrm{C}$; (e) $800^{\circ} \mathrm{C}$.
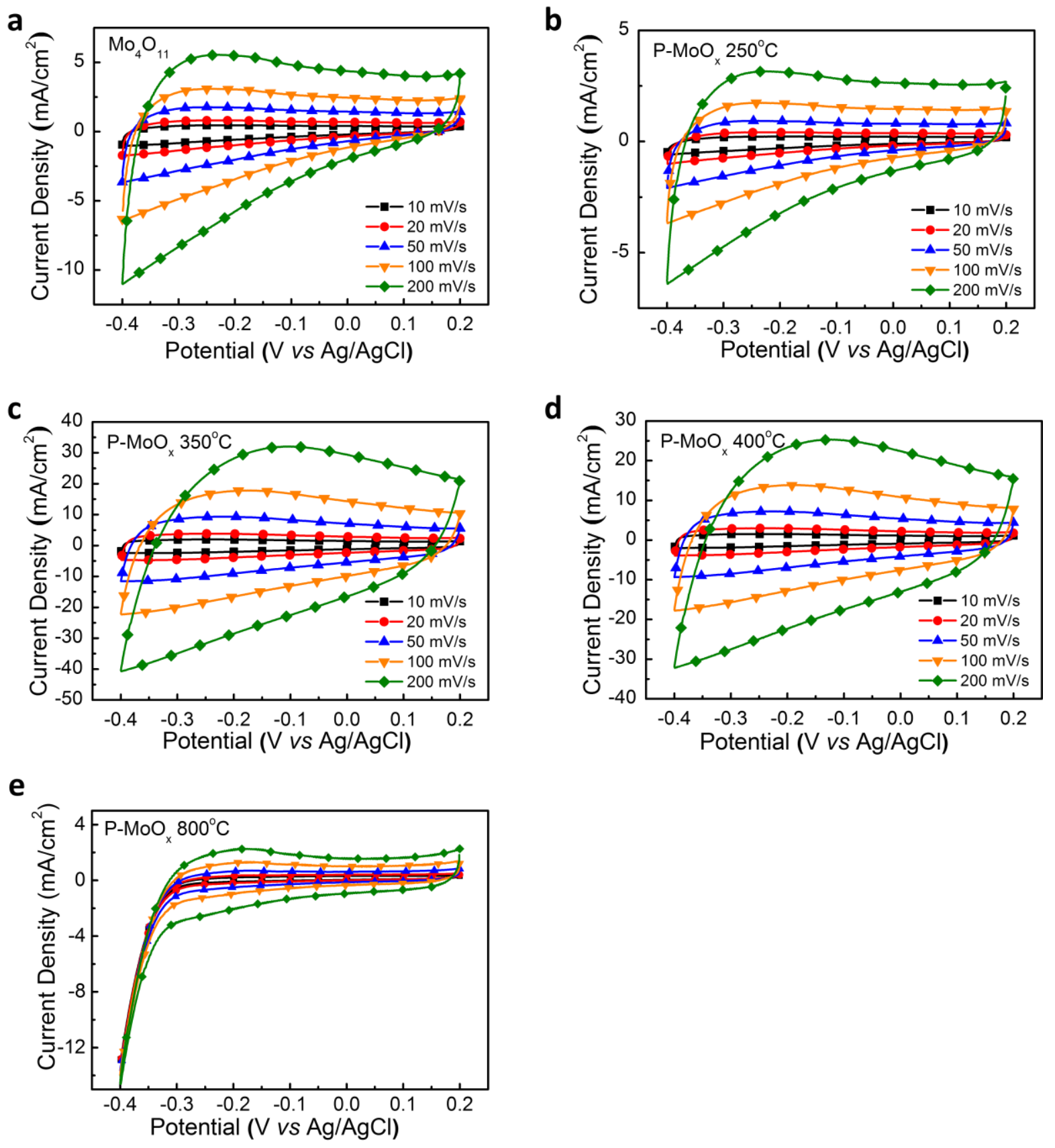
Figure S16 Post-mortem SEM analysis of MoP-protected $\mathrm{MoO}_{x}$ NTs phosphidized at $300^{\circ} \mathrm{C}$, and tested for performance degradation over $10^{\prime} 000$ consecutive CV cycles (at $100 \mathrm{mV} \mathrm{s}^{-1}$ ).
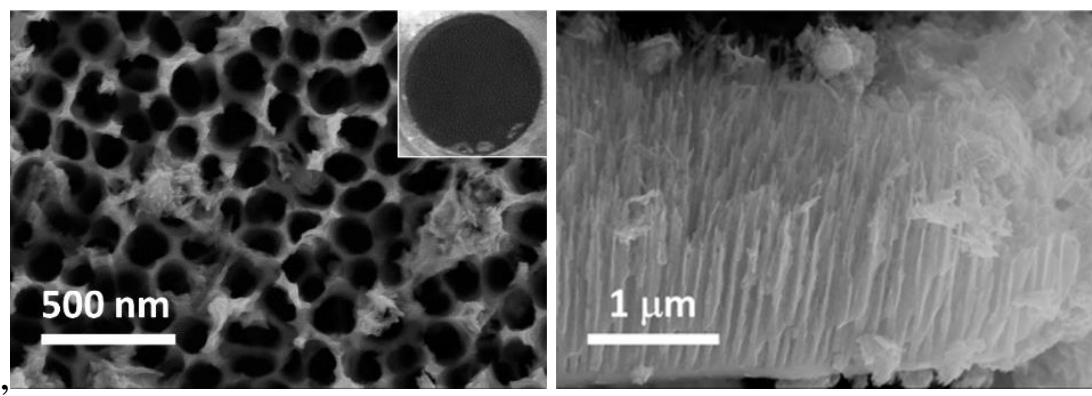

Figure S17 Post-mortem EIS results (Nyquist and (inset) Bode plots) of (a) MoP-protected $\mathrm{MoO}_{\mathrm{x}}$ NTs phosphidized at $300^{\circ} \mathrm{C}$, and (b) $\mathrm{Mo}_{4} \mathrm{O}_{11} \mathrm{NTs}$, i.e. crystallized in vacuum at $350^{\circ} \mathrm{C}$, tested for assessing their cycling stability and performance degradation over $10^{\prime} 000$ consecutive CV cycles (at $\left.100 \mathrm{mV} \mathrm{s}^{-1}\right)$.
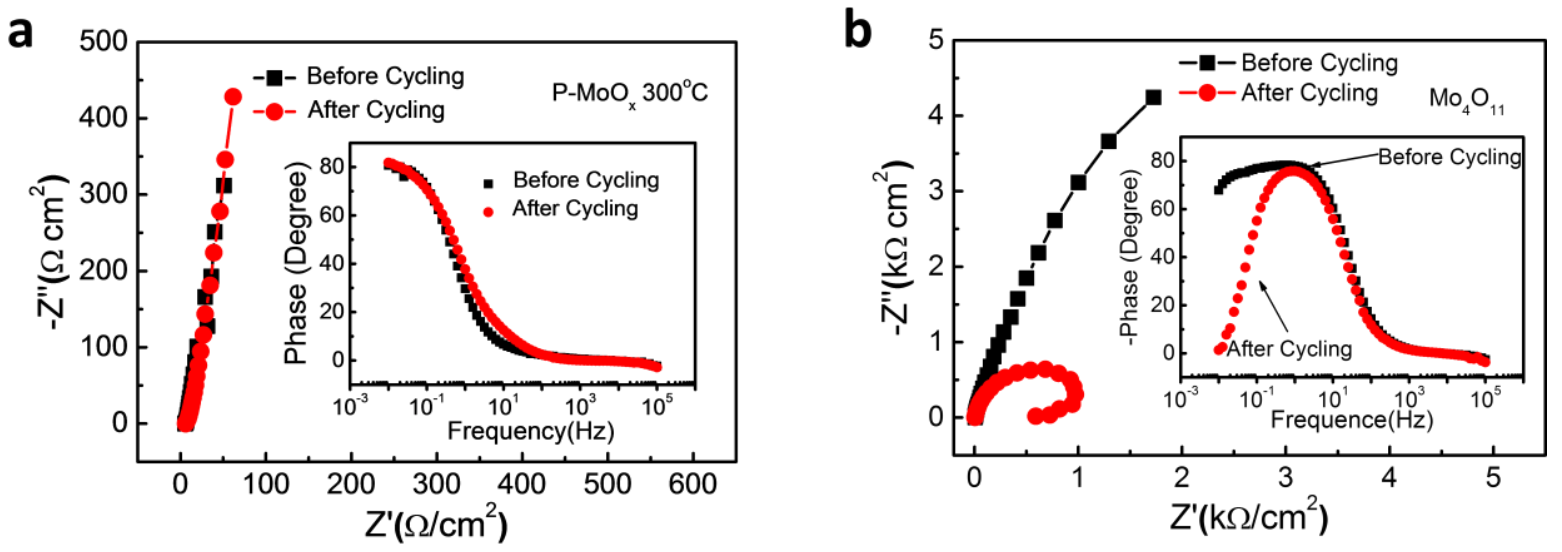
Table S1 Chemical composition (determined by EDS-SEM analysis) of NTs crystallized and MoPprotected at different temperatures.

\begin{tabular}{llllllll}
\hline & $\begin{array}{l}\mathrm{As}-f o r m e d \\
\mathrm{MoO}_{x}\end{array}$ & $\mathrm{Mo}_{4} \mathrm{O}_{11}$ & $\begin{array}{l}\mathrm{P}-\mathrm{MoO}_{x} \\
250^{\circ} \mathrm{C}\end{array}$ & $\begin{array}{l}\mathrm{P}-\mathrm{MoO}_{x} \\
300^{\circ} \mathrm{C}\end{array}$ & $\begin{array}{l}\mathrm{P}-\mathrm{MoO}_{x} \\
350^{\circ} \mathrm{C}\end{array}$ & $\begin{array}{l}\mathrm{P}-\mathrm{MoO}_{x} \\
400^{\circ} \mathrm{C}\end{array}$ & $\begin{array}{l}\mathrm{P}-\mathrm{MoO}_{x} \\
800^{\circ} \mathrm{C}\end{array}$ \\
\hline $\begin{array}{l}\mathrm{OKK} \\
\text { (at\%) }\end{array}$ & 50.93 & 53.53 & 48.01 & 30.89 & 31.70 & 27.37 & 17.90 \\
$\begin{array}{l}\mathrm{PK} \\
\text { (at\%) }\end{array}$ & $/$ & $/$ & 1.83 & 30.68 & 27.62 & 26.40 & 26.39 \\
$\begin{array}{l}\mathrm{MoL} \\
\text { (at\%) }\end{array}$ & 49.07 & 46.47 & 50.16 & 32.85 & 35.99 & 41.41 & 55.71 \\
$\begin{array}{l}\mathrm{NaK} \\
\text { (at\%) }\end{array}$ & $/$ & $/$ & $/$ & 5.57 & 4.69 & 4.81 & $/$ \\
\hline
\end{tabular}

Table S2 Mo content (at\%) and oxidation state (XPS analysis) for NTs crystallized and MoPprotected at different temperatures.

\begin{tabular}{llllll}
\hline & $\mathrm{Mo}_{4} \mathrm{O}_{11}$ & $\begin{array}{l}\mathrm{P}-\mathrm{MoO}_{x} \\
250^{\circ} \mathrm{C}\end{array}$ & $\begin{array}{l}\mathrm{P}-\mathrm{MoO}_{x} \\
300^{\circ} \mathrm{C}\end{array}$ & $\begin{array}{l}\mathrm{P}-\mathrm{MoO}_{x} \\
350^{\circ} \mathrm{C}\end{array}$ & $\begin{array}{l}\mathrm{P}-\mathrm{MoO}_{x} \\
400^{\circ} \mathrm{C}\end{array}$ \\
\hline $\mathrm{Mo}^{6+}$ & 0.62 & 0.62 & 0 & 0 & 0 \\
$\mathrm{Mo}^{5+}$ & 0.38 & 0.38 & 0.11 & 0.06 & 0.07 \\
$\mathrm{Mo}^{4+}$ & 0 & 0 & 0.34 & 0.24 & 0.20 \\
$\mathrm{Mo}^{\delta+}$ & 0 & 0 & 0.55 & 0.67 & 0.71 \\
$\mathrm{Mo}^{0}$ & 0 & 0 & 0 & 0.03 & 0.02 \\
\hline
\end{tabular}


Table S3 Overview of most recent volumetric capacitances reported in the literature for various class of materials.

\begin{tabular}{|c|c|c|c|c|}
\hline Reference & Material & $\begin{array}{l}\text { Measurement } \\
\text { condition }\end{array}$ & $\begin{array}{l}\text { Volumetric } \\
\text { Capacitance }\end{array}$ & $\begin{array}{c}\text { Mass } \\
\text { Capacitance }\end{array}$ \\
\hline Nat. Nanotechnol. 2011, 6, 232 & $\begin{array}{l}\text { Nanoporous } \\
\text { Gold/MnO}{ }_{2}^{2}\end{array}$ & $50 \mathrm{mV} / \mathrm{s}$ & $1160 \mathrm{~F} / \mathrm{cm}^{3}$ & \\
\hline Science 2013, 341, 1502 & $\mathrm{Ti}_{3} \mathrm{C}_{2} \mathrm{~T}_{\mathrm{x}}{ }^{3}$ & $1 \mathrm{~A} / \mathrm{g}$ & $350 \mathrm{~F} / \mathrm{cm}^{3}$ & $\begin{array}{c}130 \mathrm{~F} / \mathrm{g}(2 \\
\mathrm{mV} / \mathrm{s})\end{array}$ \\
\hline Nature 2014, 516, 78 & $\mathrm{Ti}_{3} \mathrm{AlC}_{2}{ }^{4}$ & $2 \mathrm{mV} / \mathrm{s}$ & $900 \mathrm{~F} / \mathrm{cm}^{3}$ & $250 \mathrm{~F} / \mathrm{g}$ \\
\hline $\begin{array}{c}\text { Nature Nanotechnology 2015, 10, } \\
313\end{array}$ & $\mathrm{MoS}_{2}{ }^{5}$ & $2 \mathrm{mV} / \mathrm{s}$ & $650 \mathrm{~F} / \mathrm{cm}^{3}$ & \\
\hline Advanced Materials 2015, 27, 8082 & $\begin{array}{c}\text { Graphene/Polyaniline } \\
6\end{array}$ & $0.5 \mathrm{~A} / \mathrm{g}$ & $800 \mathrm{~F} / \mathrm{cm}^{3}$ & $550 \mathrm{~F} / \mathrm{g}$ \\
\hline $\begin{array}{c}\text { Angewandte Chemie-International } \\
\text { Edition 2015, 54, } 8100\end{array}$ & $\begin{array}{l}\text { Nanoporous NiCuMn } \\
\text { Oxy-hydroxide }\end{array}$ & $0.25 \mathrm{~A} / \mathrm{cm}^{3}$ & $627 \mathrm{~F} / \mathrm{cm}^{3}$ & 1097 F/g \\
\hline $\begin{array}{c}\text { Advanced Energy Materials 2017, 7, } \\
1700766\end{array}$ & $\begin{array}{l}\text { Nitrogen doped } \\
\text { graphene }^{8}\end{array}$ & $0.5 \mathrm{~A} / \mathrm{g}$ & $600 \mathrm{~F} / \mathrm{cm}^{3}$ & $500 \mathrm{~F} / \mathrm{g}$ \\
\hline Nano Letters 2017, 17, 1365 & Compact graphene ${ }^{9}$ & $0.5 \mathrm{~A} / \mathrm{g}$ & $711 \mathrm{~F} / \mathrm{cm}^{3}$ & $450 \mathrm{~F} / \mathrm{g}$ \\
\hline $\begin{array}{l}\text { Journal of Materials Chemistry A } \\
\qquad 2017,5,16689\end{array}$ & Graphene/PANI ${ }^{10}$ & $0.5 \mathrm{~A} / \mathrm{g}$ & $1058 \mathrm{~F} / \mathrm{cm}^{3}$ & $750 \mathrm{~F} / \mathrm{g}$ \\
\hline Nature Energy 2017, 2, 10175 & MXene/Graphene $\mathrm{e}^{11}$ & $2 \mathrm{mV} / \mathrm{s}$ & $1500 \mathrm{~F} / \mathrm{cm}^{3}$ & $375 \mathrm{~F} / \mathrm{g}$ \\
\hline Small 2017, 13,1701026 & $\mathrm{RuO}_{2} / \mathrm{Graphene}^{12}$ & $0.1 \mathrm{~A} / \mathrm{g}$ & $1485 \mathrm{~F} / \mathrm{cm}^{3}$ & $580 \mathrm{~F} / \mathrm{g}$ \\
\hline $\begin{array}{c}\text { Advanced Functional Materials } \\
2017,27,1702160\end{array}$ & $\mathrm{NiCO}_{2} \mathrm{O}_{4} @ \mathrm{CNT} / \mathrm{CNT}^{13}$ & $\begin{array}{l}0.5 \mathrm{~A} / \mathrm{g} \\
2 \mathrm{mV} / \mathrm{s}\end{array}$ & $\begin{array}{l}873 \mathrm{~F} / \mathrm{cm}^{3} \\
795 \mathrm{~F} / \mathrm{cm}^{3}\end{array}$ & $1177 \mathrm{~F} / \mathrm{g}$ \\
\hline $\begin{array}{l}\text { Journal of Materials Chemistry A } \\
\qquad 2018,6,36\end{array}$ & $\mathrm{CO}_{3} \mathrm{O}_{4} \mathrm{Nanosheets}^{14}$ & $12 \mathrm{~A} / \mathrm{cm}^{3}$ & $376 \mathrm{~F} / \mathrm{cm}^{3}$ & - \\
\hline $\begin{array}{c}\text { Advanced Functional Materials } \\
2018,28,1703808\end{array}$ & $\begin{array}{l}\text { Mo1.33C Mxene } \\
\text { /PEDOT:PSS }{ }^{15}\end{array}$ & $2 \mathrm{mV} / \mathrm{s}$ & $1310 \mathrm{~F} / \mathrm{cm}^{3}$ & - \\
\hline $\begin{array}{l}\text { Advanced Energy Materials 2018, 8, } \\
\qquad 1800227\end{array}$ & Graphene/MoS ${ }^{16}$ & $\begin{array}{c}1 \mathrm{~A} / \mathrm{g} \\
0.5 \mathrm{~A} / \mathrm{cm}^{3}\end{array}$ & $1431 \mathrm{~F} / \mathrm{cm}^{3}$ & $707 \mathrm{~F} / \mathrm{g}$ \\
\hline $\begin{array}{c}\text { ACS Appl. Mater. interfaces 2018, } \\
\text { 10, } 25949\end{array}$ & 2D mixed MXenes ${ }^{17}$ & $2 \mathrm{mV} / \mathrm{s}$ & $1514 \mathrm{~F} / \mathrm{cm}^{3}$ & $435 \mathrm{~F} / \mathrm{g}$ \\
\hline
\end{tabular}




\begin{tabular}{|c|c|c|c|c|}
\hline $\begin{array}{l}\text { J. Mater. Chem. A, 2018, 6, } \\
\qquad 22123\end{array}$ & MXene/PANI ${ }^{18}$ & $2 \mathrm{mV} / \mathrm{s}$ & $1682 \mathrm{~F} / \mathrm{cm}^{3}$ & 503 F/g \\
\hline $\begin{array}{l}\text { Nature communications } \\
\qquad 2018,9,1375\end{array}$ & $\mathrm{NPC}-\mathrm{V}_{2} \mathrm{O}_{3} / \mathrm{r}-\mathrm{VO}_{2-\mathrm{x}}{ }^{19}$ & $\begin{array}{c}5 \mathrm{mV} / \mathrm{s} \\
1 \mathrm{~A} / \mathrm{g}\end{array}$ & $\begin{array}{l}1933 \mathrm{~F} / \mathrm{cm}^{3} \\
1353 \mathrm{~F} / \mathrm{cm}^{3}\end{array}$ & $1856 \mathrm{~F} / \mathrm{g}$ \\
\hline This work & MoP-MoOx NTs & $\begin{array}{c}1 \mathrm{~A} / \mathrm{cm}^{3} \\
(0.4 \mathrm{~A} / \mathrm{g}) \\
10 \mathrm{mV} / \mathrm{s}\end{array}$ & $\begin{array}{l}2044 \mathrm{~F} / \mathrm{cm}^{3} \\
1514 \mathrm{~F} / \mathrm{cm}^{3}\end{array}$ & $\begin{array}{c}817.6 \mathrm{~F} / \mathrm{g} \\
600 \mathrm{~F} / \mathrm{g}\end{array}$ \\
\hline
\end{tabular}

\section{References}

1 J. M. McEnaney, J. C. Crompton, J. F. Callejas, E. J. Popczun, A. J. Biacchi, N. S. Lewis and R. E. Schaak, Chemistry of Materials, 2014, 26, 4826-4831.

2 P. Simon and Y. Gogotsi, Nature nanotechnology, 2011, 6, 232-236.

3 M. R. Lukatskaya, O. Mashtalir, C. E. Ren, Y. Dall'Agnese, P. Rozier, P. L. Taberna, M. Naguib, P. Simon, M. W. Barsoum and Y. Gogotsi, Science, 2013, 341, 1502-1505.

4 M. Ghidiu, M. R. Lukatskaya, M.-Q. Zhao, Y. Gogotsi and M. W. Barsoum, Nature, 2014, 516, 78.

$5 \quad$ M. Acerce, D. Voiry and M. Chhowalla, Nature Nanotechnology, 2015, 10, 313-318.

6 Y. Xu, Y. Tao, X. Zheng, H. Ma, J. Luo, F. Kang and Q. Yang, Advanced materials, 2015, 27, 8082-8087.

7 J. Kang, A. Hirata, L. Chen, S. Zhu, T. Fujita and M. Chen, Angewandte Chemie International Edition, 2015, 127, 8218-8222.

8 S. Lin, C. Zhang, Z. Wang, S. Dai and X. Jin, Advanced Energy Materials, 2017, 7, 1700766.

9 G. Lian, C.-C. Tuan, L. Li, S. Jiao, K.-S. Moon, Q. Wang, D. Cui and C.-P. Wong, Nano letters, 2017, 17, 1365-1370.

10 Z. Fan, Z. Cheng, J. Feng, Z. Xie, Y. Liu and Y. Wang, Journal of Materials Chemistry A, 2017, 5, 16689-16701.

11 M. R. Lukatskaya, S. Kota, Z. Lin, M.-Q. Zhao, N. Shpigel, M. D. Levi, J. Halim, P.-L. Taberna, M. W. Barsoum and P. Simon, Nature Energy, 2017, 2, 17105.

12 H. Ma, D. Kong, Y. Xu, X. Xie, Y. Tao, Z. Xiao, W. Lv, H. D. Jang, J. Huang and Q. Yang, Small, 2017, 13, 1701026.

13 P. Wu, S. Cheng, M. Yao, L. Yang, Y. Zhu, P. Liu, O. Xing, J. Zhou, M. Wang and H. Luo, Advanced Functional Materials, 2017, 27, 1702160.

14 S. Kalasina, N. Phattharasupakun and M. Sawangphruk, Journal of Materials Chemistry A, 2018, 6, 36-40.

15 L. Qin, Q. Tao, A. El Ghazaly, J. Fernandez-Rodriguez, P. O. Å. Persson, J. Rosen and F. Zhang, Advanced Functional Materials, 2018, 28, 1703808.

16 H. Jeon, J. Jeong, H. G. Kang, H. Kim, J. Park, D. H. Kim, Y. M. Jung, S. Y. Hwang, Y. Han and B. G. Choi, Advanced Energy Materials, 2018, 8, 1800227.

17 E. Kayali, A. VahidMohammadi, J. Orangi and M. Beidaghi, ACS applied materials \& interfaces, 2018, 10, 25949-25954.

18 A. VahidMohammadi, J. Moncada, H. Chen, E. Kayali, J. Orangi, C. A. Carrero and M. 
Beidaghi, Journal of Materials Chemistry A, 2018, 6, 22123-22133.

19 B.-T. Liu, X.-M. Shi, X.-Y. Lang, L. Gu, Z. Wen, M. Zhao and Q. Jiang, Nature communications, 2018, 9, 1375. 